\title{
الأداء الإداري لدى رؤسـاء الأقسام الأكاديمية في الجامعات الأردنية وعلاقته بتطبيق مبادئ الحوكمة
}

\author{
بشيرة حسن عقلة مقدادي \\ طالبة دكتوراة- إدارة تربوية- كلية التربية- جامعة اليرموك- الأردن \\ basheerahmiqdadi@yahoo.com \\ عدنان بدري الإبراهيم \\ أستاذ الإدارة التربوية- قسم الإدارة التربوية- كلية التربية- جامعة اليرموك- الأردن
}

هدفت الدراسة التعرف على الأداء الإداري لدى رؤساء الأقسام بالجامعات الأردنية وعلاقته بتطبيق مبادئ الحوكمة. استخدمت الدراسة المنهج الوصفي بالأسلوب المستي، وتم تطبيق استبانة مكونة من (ا7) فقرة على عينة مكونة (TrV) عضو هيئة تدريس، تم اختيارهم بالطريقة العشوائية من

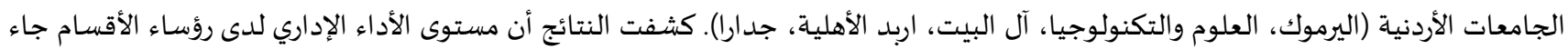

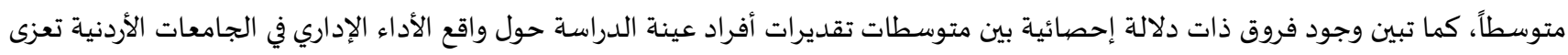

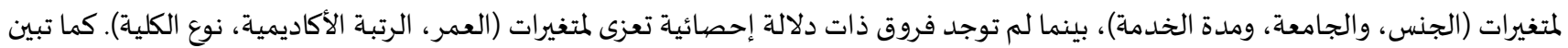

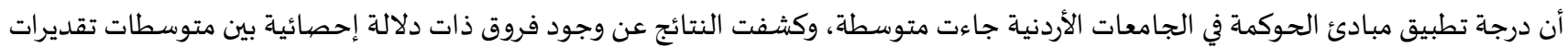

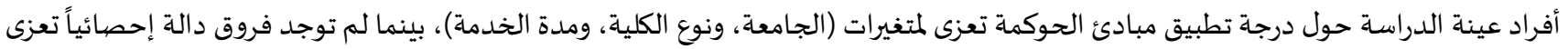

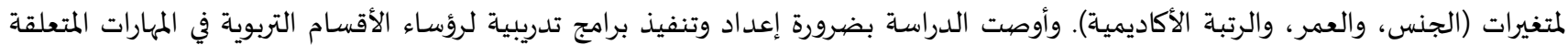
بمجالات الدراسة التي حصلت على درجة تقدير متوسطة لرفع كفاءتهم وحصولههم وامتلاكهم لهذه المهارات. واعتماد الخبرة والمعرفة - بصفتها مؤشراً المواقع الإدارية القيادية في المؤسسات الجامعية. وأن يقوم رؤساء الأقسام باستخدام صلاحياتهم في تعزيز الأداء الإيجابي لأعضاء هيئة التدريس ومحاسبة الأداء السلبي لما لذلك من دور تحفيزي فاعل. المياديه

الكلمات المفتاحية: الأداء الإداري؛ الحوكمة؛؛ رؤساء الأقسام؛ الجامعات الأردنية. (c) $(b)$

يكتسب التعليم الجامعي خاصة أهمية بالغة لكوناه من أهم معاقل الفكر والتنوير التي يتم من خلالها إعداد وتأهيل القيادات الفكرية والعلمية

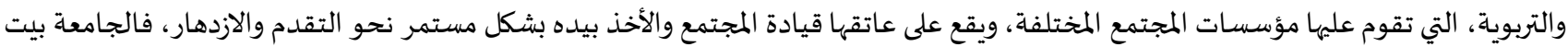

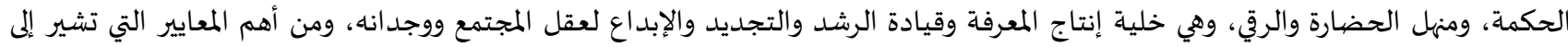

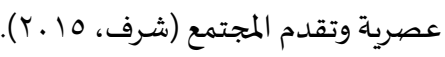

ولكي تقوم الجامعات بدورها الرائد، تحتاج إلى إدارة جامعية ناجحة متميزة تشرف على كلى نشاط جأل جامعي قيادي تربوي هادف مرن، وتعتمد على

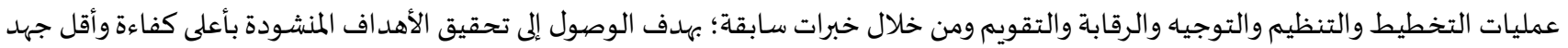

$$
\text { (الصاوي، .... ( الصياس). }
$$

وتحرص الإدارة الجامعية الناجحة على تحقيق التميز في وظائفها وفق تنظيم واضح واتصال فعال، وقرارات سليماة، وتقويم موضيوعي، ورقابة مستمرة، وأسلوب وتخطيط إداري ومالي سليم، وإذا لم تعتمد هذه الأسس في وظائف الإدارة الجامعية فإنها ستفشل في تحقيق أهدافها. 
وتكمن جدوى وفعالية جهود الإدارة الجامعية الحديثة في تعظيم قدرات وإثراء إمكانات النظام المؤسسي الجامعي، كما أن ضمان استمرارية هذا

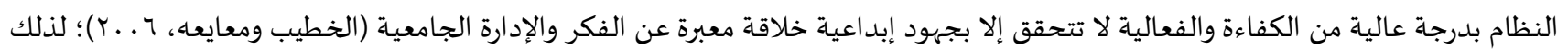

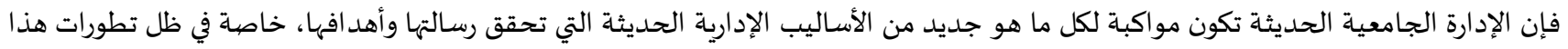

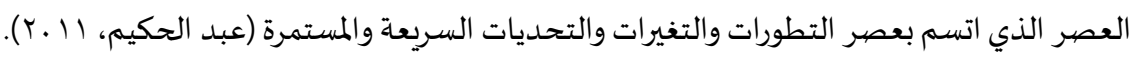

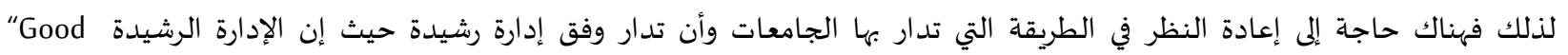

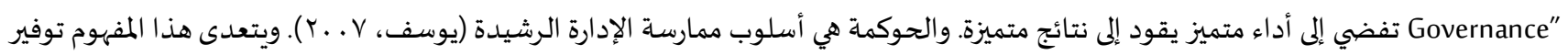

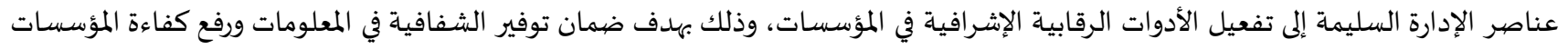

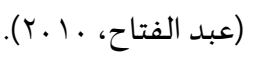

فكلمة الحوكمة مشتقة من الفعل اليوناني(kubernáo) ، والذي يعني توجياه، وقد استخدماه أفلاطون لأول مرة بالمعنى المجازي.

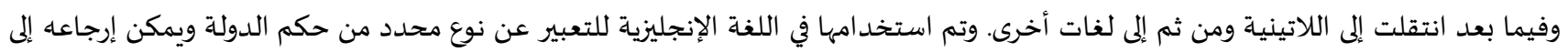

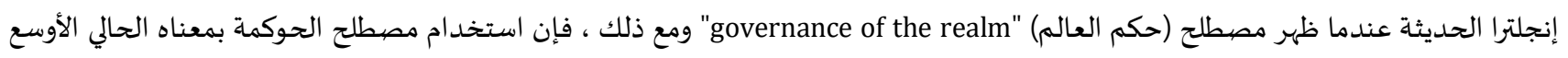

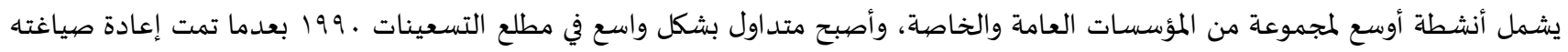

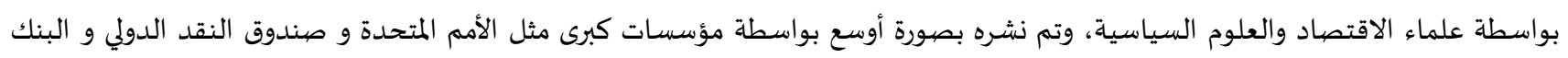
الدولي.

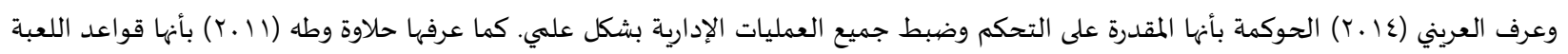

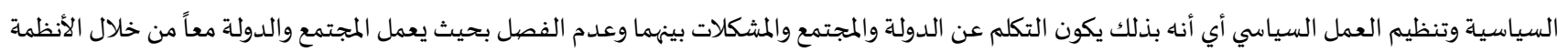
والقوانين.

أما عقلان (10 ـ ب) فقد عرفها بأنها جهد إنساني موجه لدرء الفساد وتعميم الصلاح والتميز في الأداء الإداري القائم على مبادئ العدل والمشاركة والاستقلال

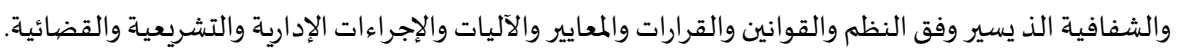

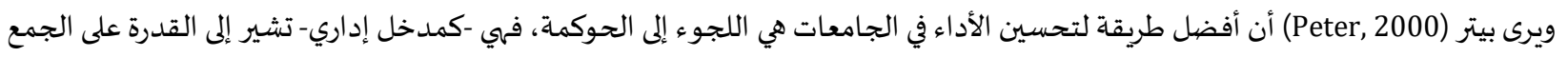
بين المؤسسات الرسمية وغير الرسمية، وإدخالها في عملية صنع القرار وتنفيذه.

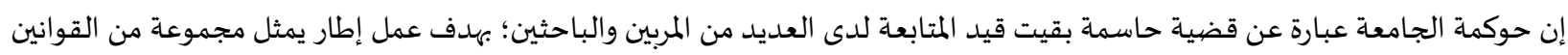

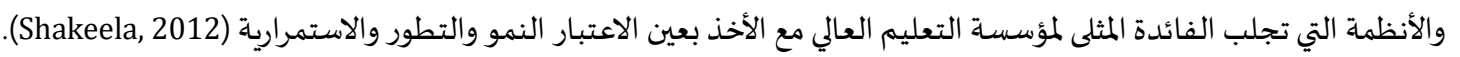

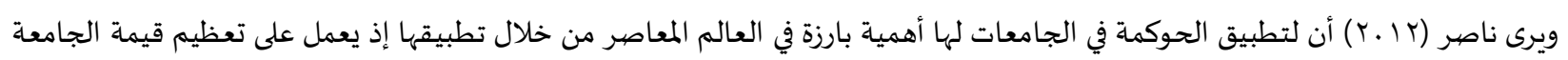
ومقدرتها التنافسية وبخاصة في مجال مخرجاتها، كما تعمل على تحديد الاتجاه الذي تسلكه الجامعات عن طريق اتخاذ التهاذ القرارات الصائبة والمناسبة للحفاظ على الموارد البشرية والمادية والمعنوية.

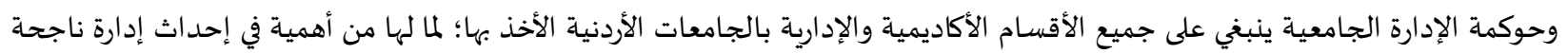

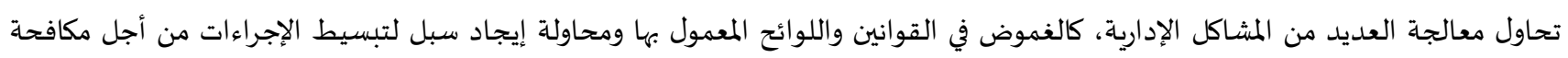

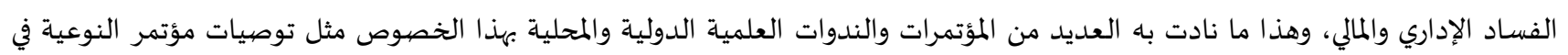

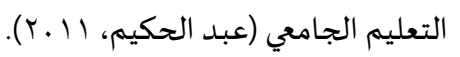

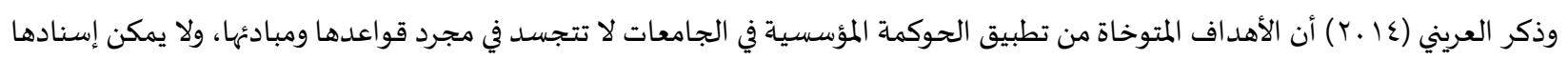

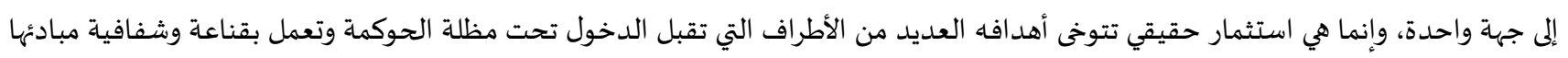

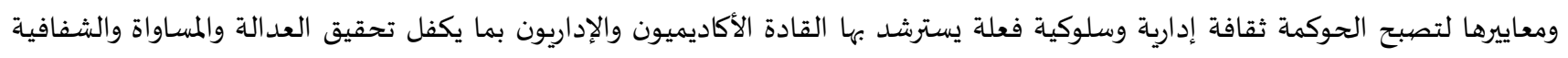

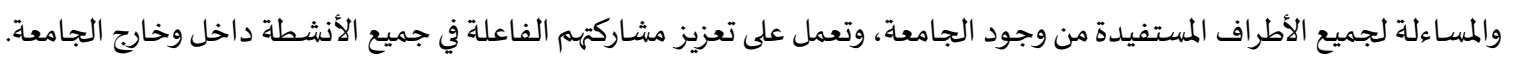

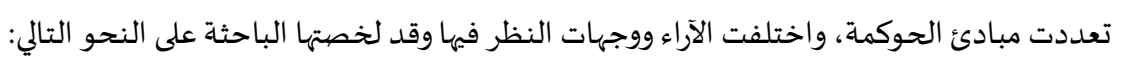

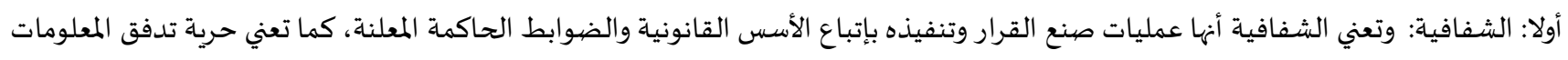

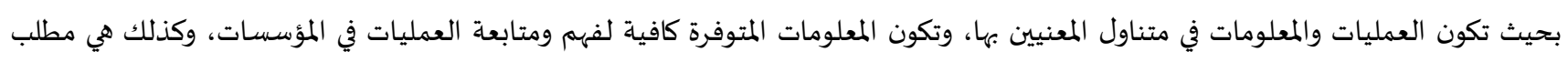

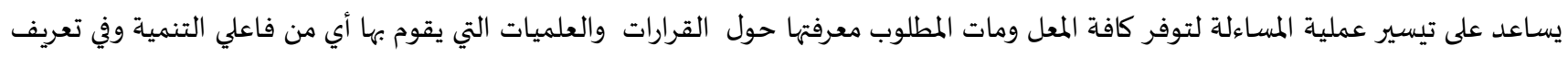

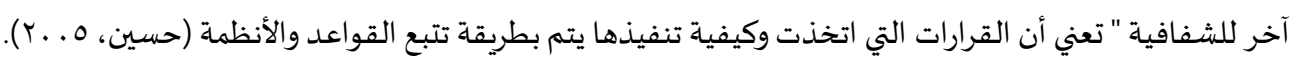

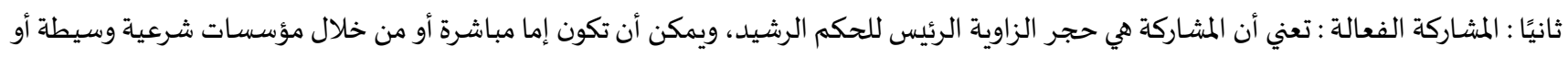

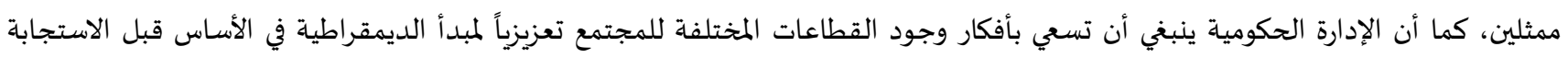


لضغوط خارجية من المؤسسات الدولية المانحة، لأنها بذلك تكتسب صفة المصداقية في صنع وتنفيذ السياسات العامة، والمشاركة لابد وأن يكون لها

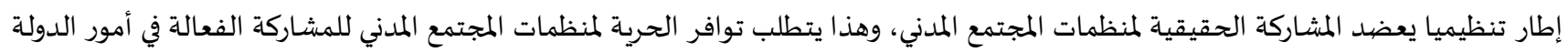

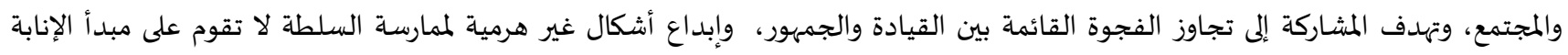

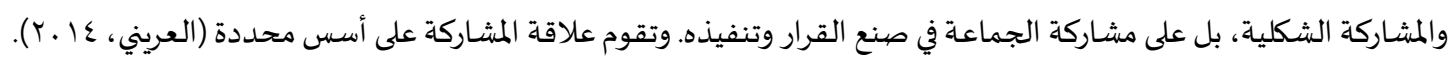

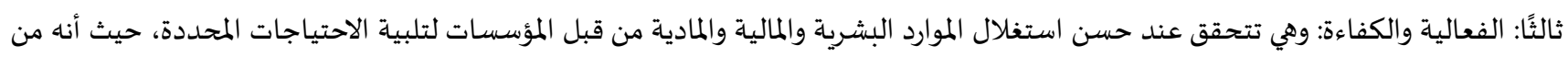

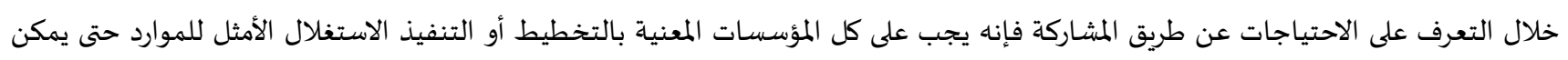

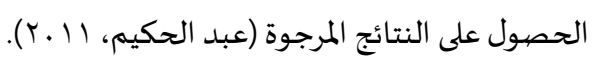

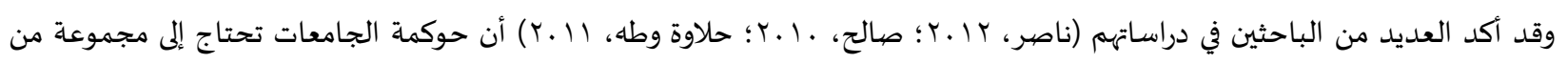

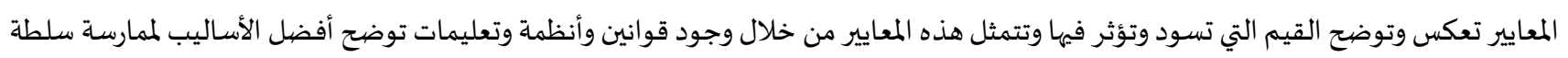

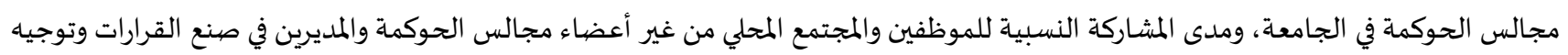

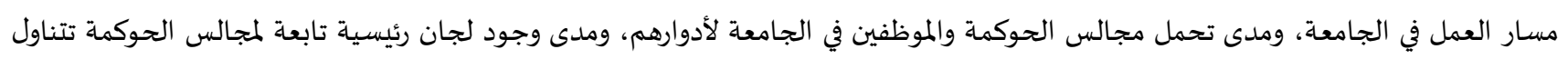

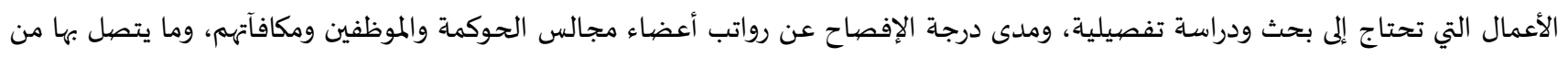
إنجازات وأعمال تم القيام بها، ودرجة تطبيق معايير الجودة.

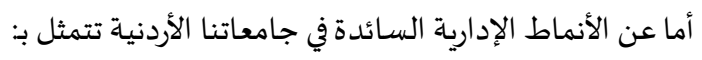

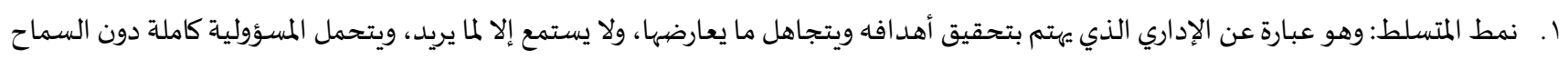

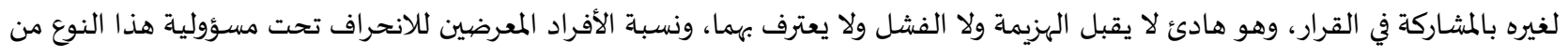

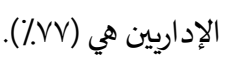

r. نمط الديموقراطي :وهو الإداري الذي يشارك الآخرين في تحقيق الأهداف ويستمع للحوار ويقبل ترجيح الرأي بالتصيويت، عاطفي، ويسمح بالمشاركة

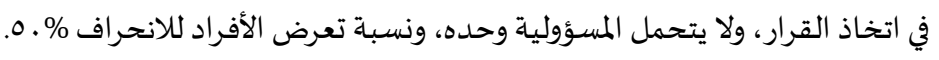

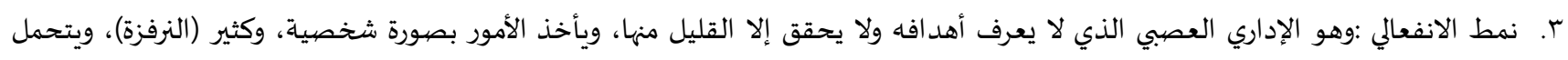

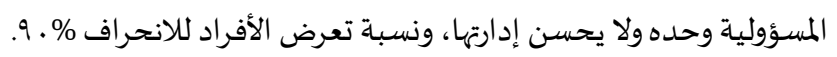

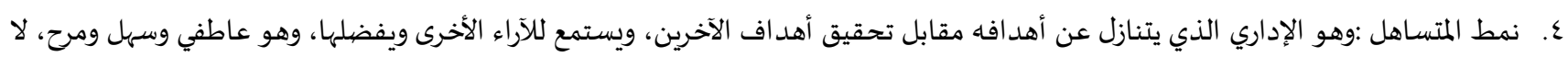

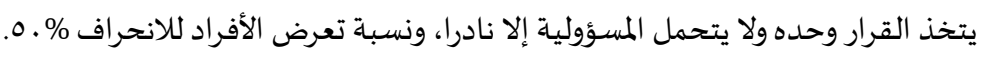

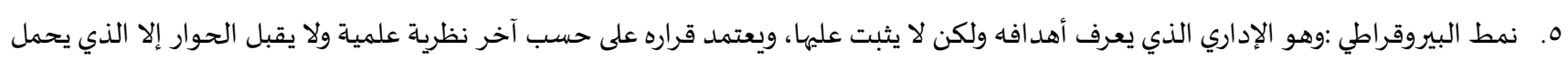

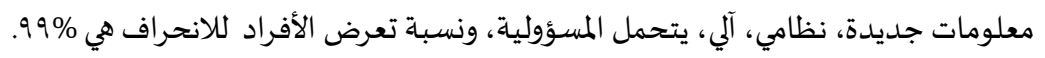

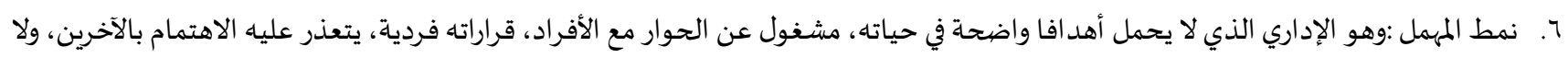

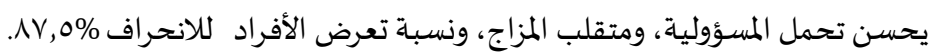

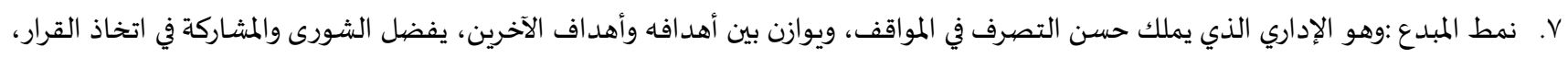

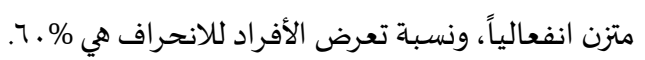

مشكلة الدراسـة: تزايد في السنوات الأخيرة الاهتمام بموضوع الحوكمة في مؤسسات التعليم العالي من خلال عقد المؤتمرات التي كانت توصي الإسراع في تطبيق

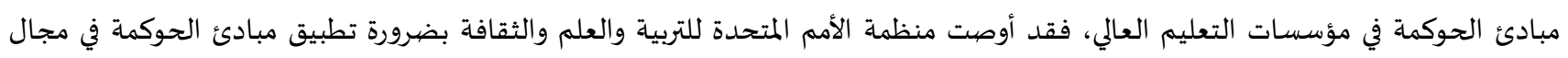

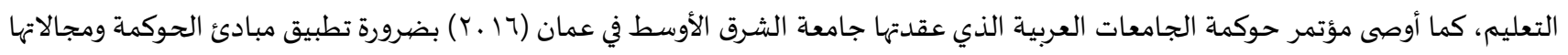

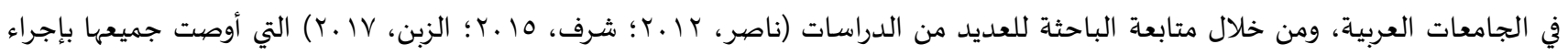

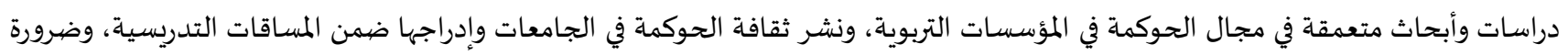

قيام المسؤولين في وزارة التعليم العالي والبحث العلمي الأردنية بعقد دورات للقادة الأكاديميين حول موضيوع الحوكية الحوكمة.

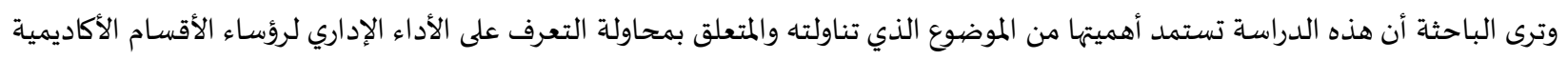

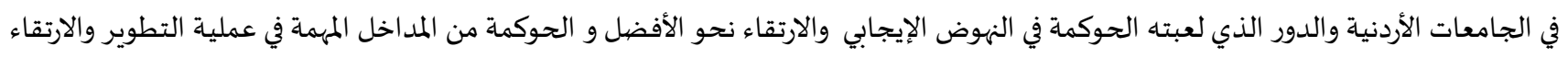

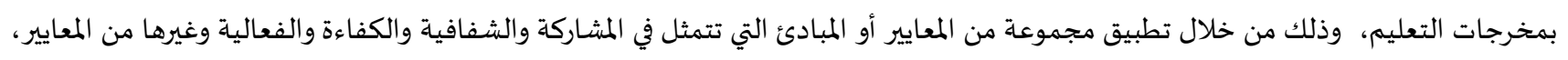


وتطبيق هذه المبادئ له أهمية بالغة في تطوير الإدارة الجامعية بأقسامها المختلفة، سواء أكان الإداري أو الأكاديمي و هنا سوف نركز على الجانب

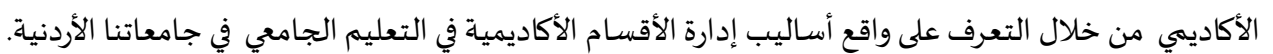
مما سبق تكمن مشكلة الدراسـة في الإجابة عن الأسئلة التالية:

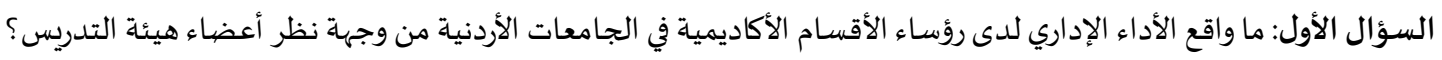

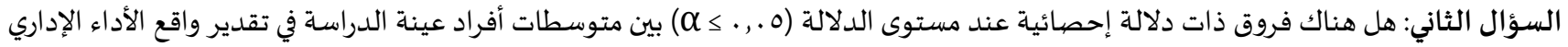

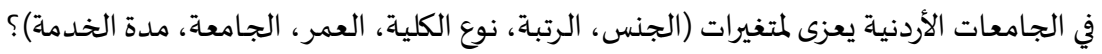

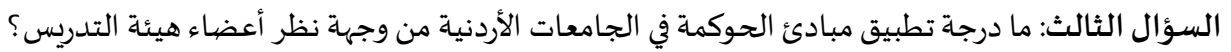
السؤال الر ابع: هل هناك فروق ذات دلالة إحصائية عند مستوى الدلالة (ه ., ـ $\alpha)$ بين متوسطات أفراد عينة الدراسة في تحديد درجة تطبيق

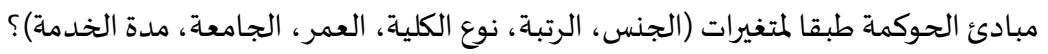
حدود الدراسة: الحدود المكانية: (جامعة اليرموك وجامعة العلوم والتكنولوجيا وجامعة آل البيت وجامعة إببد الأهلية وجامعة جدارا في المملكة الأردنية

تكمن أهميـة الدراسـة ومبرراتها في أنها: ا. سـوف تتناول موضوع الحوكمة كأحد الموضوعات المثثارة حالياً على ساحة البحث العلمي ولها تأثير مباشر على كفاءة المؤسسات باختلاف أنواعها.

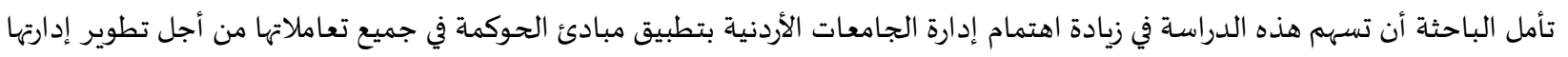
نحو متطلبات التميز. r. قد تساعد هذه الدراسة القائمين على تطوير الإدارة الجامعية في المملكة الأردنية الهاشمية وتحسينها من خلال ما تعرضها الدراسة من توصيات

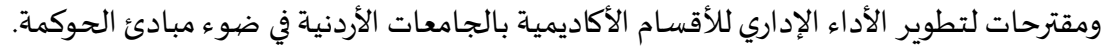

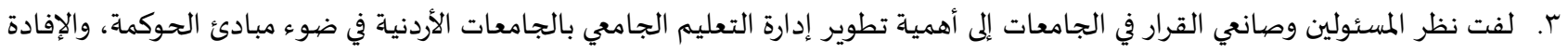
من مميزات هذا المنهج العلمي كأسلوب إداري جديد يحقق متطلبات التميز ومتطلبات التنافسية العالمية.

مصططحات الدراسـة:

الأداء الإداري: التزام الموظف بواجبات وظيفته وقيامه بالمهام المسندة إليه من خلال أدائه لمهام وظيفته وتحمله للأعباء والمسئوليات الوظيفية

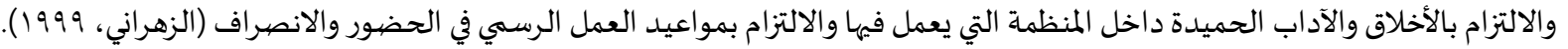
• الحوكمة: مجموعة من القوانين والنظم والقرارات التي تهدف إلى تحقيق الجودة والتميز في الأداء عن طريق اختيار الأساليب المناسبة والفعالة

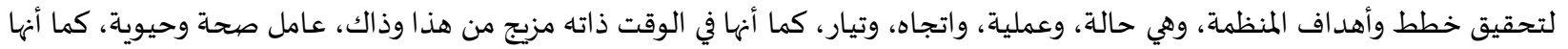


نظام مناعاة وحماية وتفعيل، نظام يحكم الحركة، ويضبط الاتجاه، ويحمي ويؤمن سلامة كافة التصرفات، ونزاهة السلوكيات داخل المؤسسات

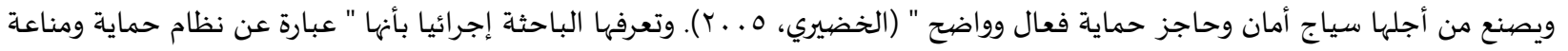
يحتوي على مبادئ وآليات وقوانين وطرق مختلفة للحفاظ على كافة الأنظمة الد اخلية والخارجية ويتم ذلك من خلال تطبية واتهها على جميع العاملين

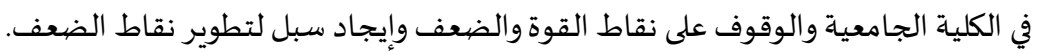

الدراسـات السـابقة:

تعددت الدراسات التي تناولت موضوعي الأداء الإداري والحوكمة كالآتي:

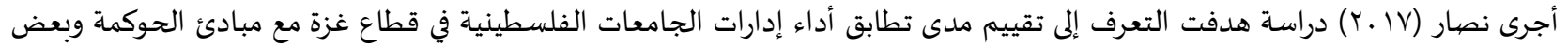

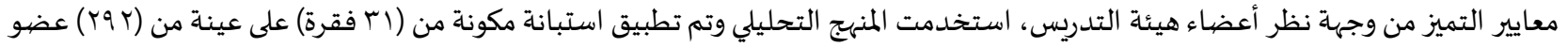

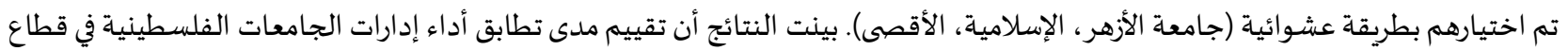

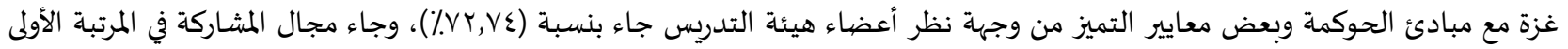

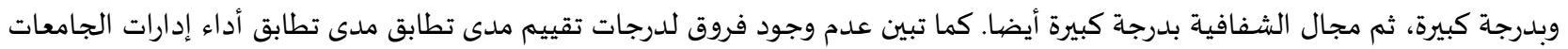
الفلسطينية في قطاع غزة مع مبادئ الحوكمة وبعض معايير التميز من وجهة نظر أعضاء هيئة التدريس تعزى لمتغيرات (الجنس، الجامعة) بينما

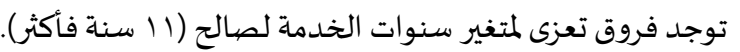

كما أجرى مسلم (7 ا ـ إ) هدفت التعرف إلى مستوى ممارسة مبادئ الحوكمة في جامعة العلوم والتكنولوجيا من وجهة نظر القيادات الأكاديمية والإدارية وطبيعة الفروق في ممارسة مبادئ الحوكمة في ضوء متغيرات الجنس والتخصص وسنوات الخدمة ونوع الوظيفة القيادية ، واقتصرت

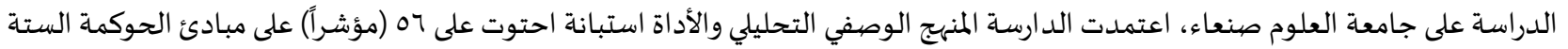
وهي: مجالس الحوكمة، المسؤولية، المساءلة، المشاركة، الإفصاح، الشفافية، الاستقلالية، ميثاق السلوك المهني، أخلاقيات العمل. بينت نتائج

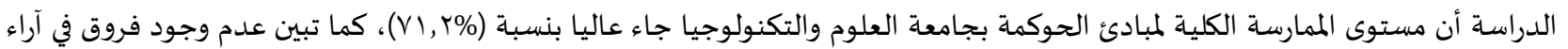
عينة الدراسة حول مستوى ممارسة الحوكمة وفقا لمتغيرات الجنس، التخصص، نوع الوظيفة القيادية وفي جميع المبادئ، ووجود فروق دمائ دالة

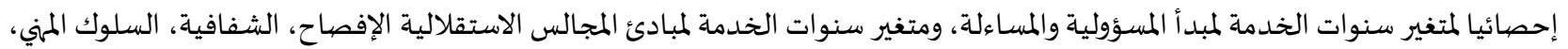

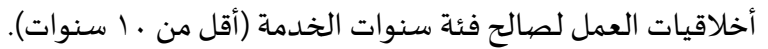
وأجرى كلاً من أبو كريم والثويني (عـا ـب) دراسة هدفت التعرف إلى درجة تطبيق مبادئ الحوكمة بكليات التربية بجامعة حائل وجامعة الملك سعود كما يراها أعضاء هيئة التدريس. تكون مجتمع الدراسـة من جميع أعضاء هيئة التدريس من حملة الدكتوراه. تكونت عينة الدراسة من (IV9)

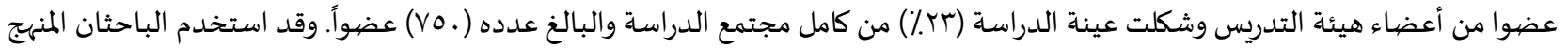

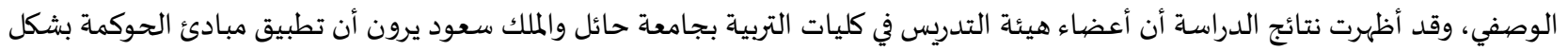
كلي متوسط إذ بلغ المتوسط الحسابي الكلي (ז,ح§). أوصى الباحثان بجملة من التوصيات منها: تطبيق مبادئ الديمقراطية في إدارة الكليات

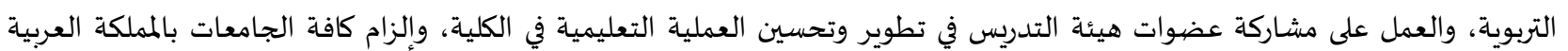
السعودياة بتحديد متطلبات الحوكمة والسعي لتطبيقه والعمل بموجباه. أما برقعان والقرشي (Y ا ـ ( فقد قاما بدراسة هدفت إلى زيادة المعرفة بمفهوم الحوكمة بشكل عام وحوكمة الجامعات بشكل خاص والتعرف على

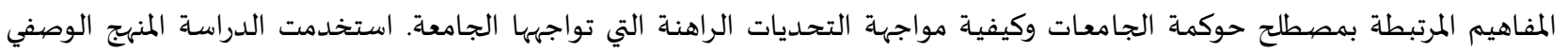

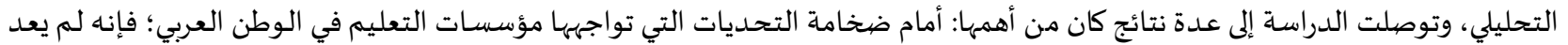

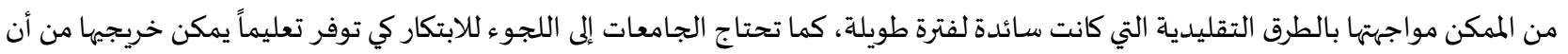
يصبحوا منافسين ويساهموا في النمو الاقتصادي والاجتماعي لبلد انهم. وكذلك تسهم حوكمة الجامعات في إيجاد مؤسسـات مسئولة عن تحديد

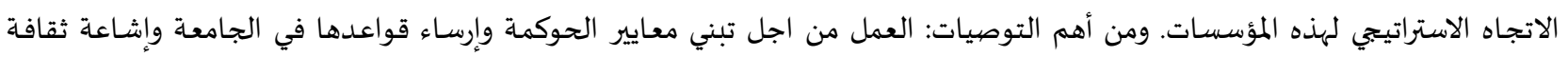

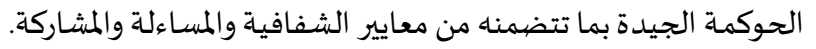

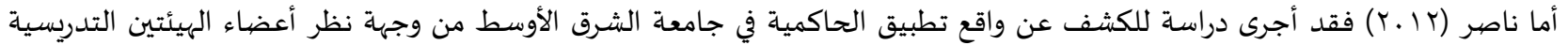

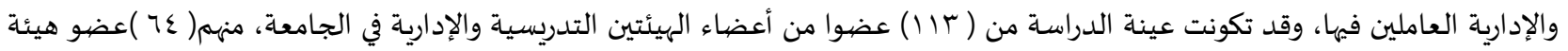
تدريس و(9 ) إدارياً، وقد اختيروا من مجتمع الدراسة المكون من( (1) ) عضو هيئة تدريس و( VN) إدارياً، بالطريقة العشوائية البسيطة ، ولجمع البيانات تم استخدام مقياس طوره الباحث تكون من( •0) فقرة، تم التأكد من صدقه وثباته ، وقد استخدم الباحث المنهج الوصيفي. وقد أشارت نتائج الدراسة إلى أن واقع تطبيق الحاكمية في جامعة الشرق الأوسط، من وجهة نظر أفراد عينة الدراسة ككل كان مرتفعا بشكل عام، كما تبين 
وجود فروق ذات دلالة إحصائية في واقع تطبيق الحاكمية في جامعة الشرق الأوسط، تبعا لاختلاف المركز الوظيفي، وكان لصالح أعضاء هيئة

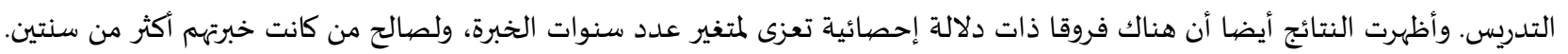

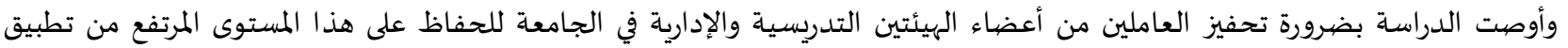

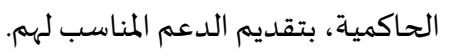
وقام ناغا (V.R. Naga,2012) بإجراء دراسة هدفت إلى: تطبيق الحوكمة الإلكترونية في مؤسسات التعليم العالي الخاصة ووضحت دور مؤسسات

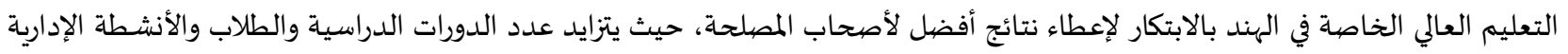

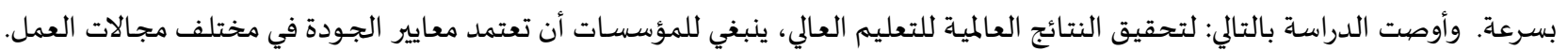

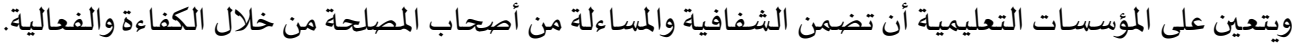

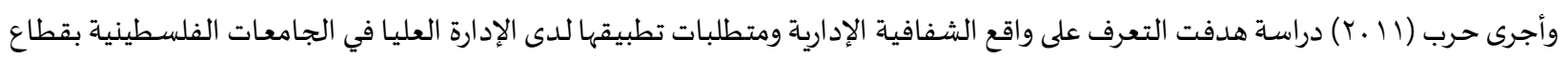

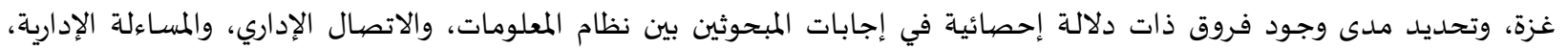

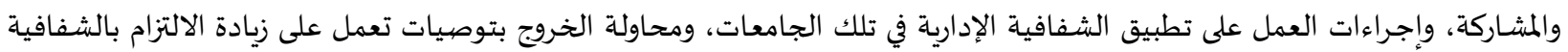

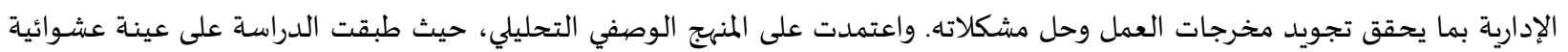

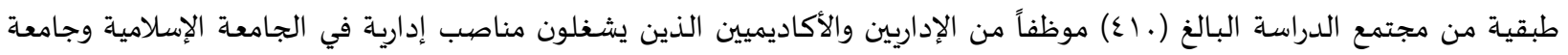

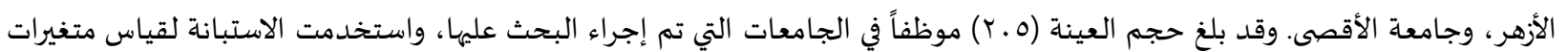

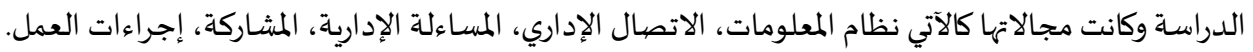

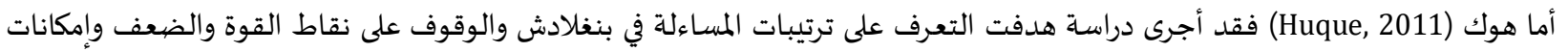

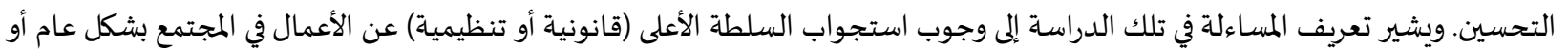

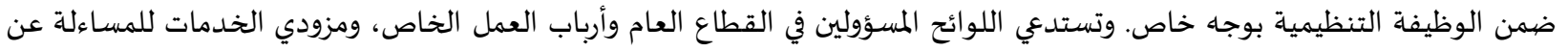

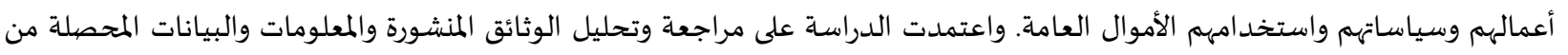

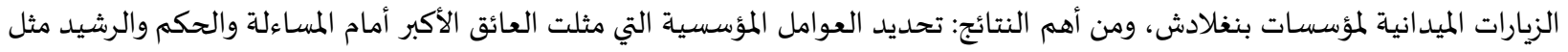

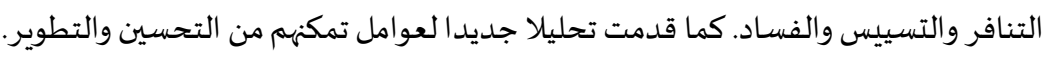

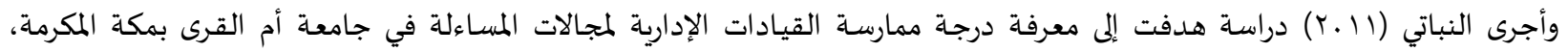

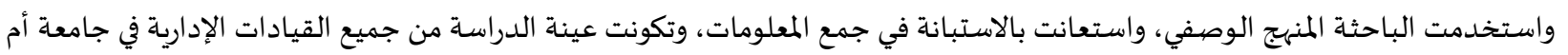

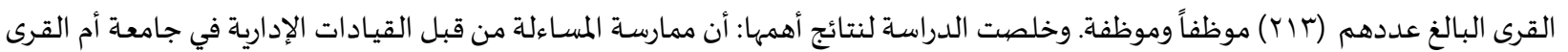

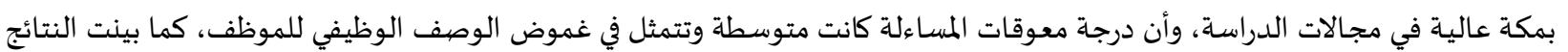

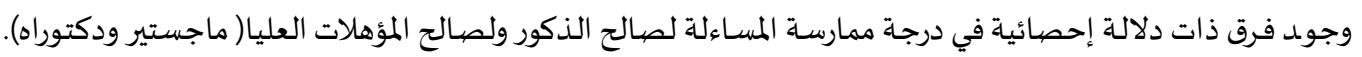
هما أجرى باترك (Patrick, 2007) دراسة وضحت تغيرات أساسية جداً في الدولة القومية، وخاصة في أوروبا التي تميزت سابقا ب "الرفاهية"

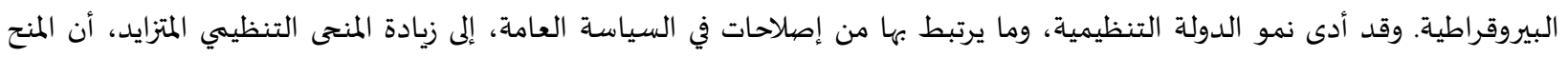

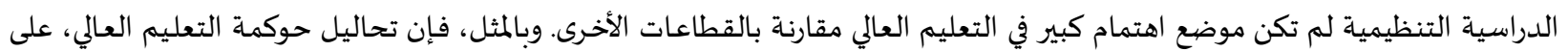

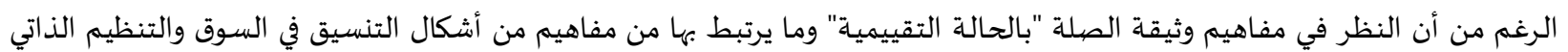

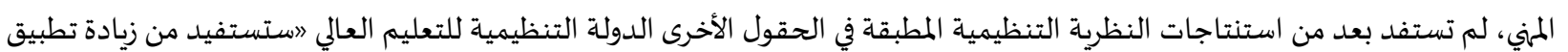
المفاهيم التنظيمية الموجودة على نطاق أوسع.

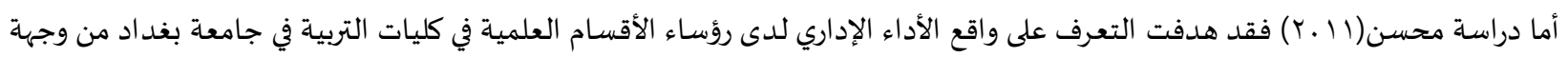

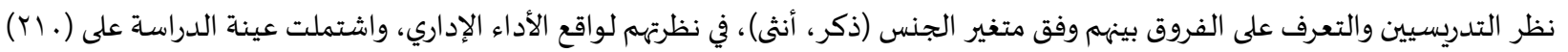

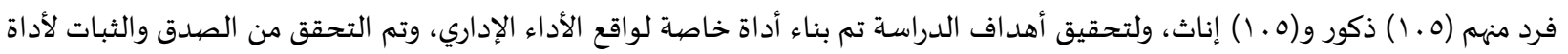

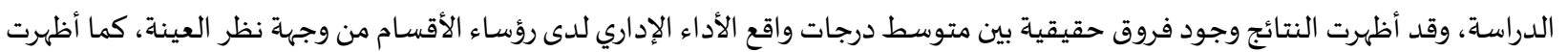

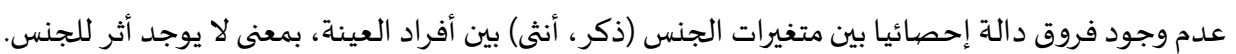

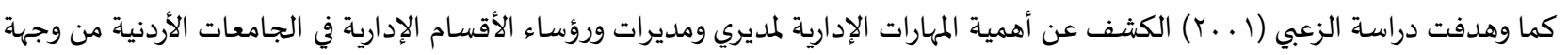

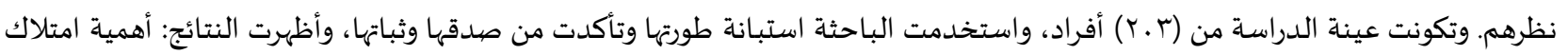




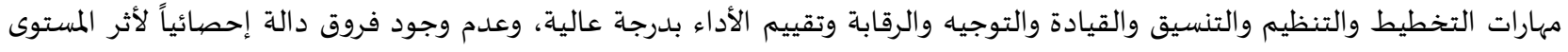
الوظيفي والتخصص والمؤهل العلمي في درجة أهمية المها ارت الإدارية.

وفي دراسـة دافيد هيلاويل ونبك هانكوك (N. Hancock \& D. Hellawell, 2001) حول تعرّف رؤساء الأقسام على إدراكهم لأدوارهم، وعن العلاقة

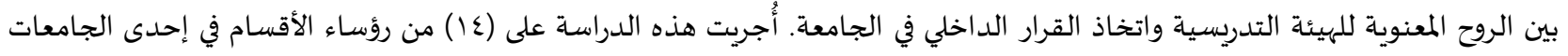

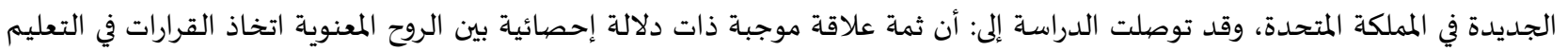

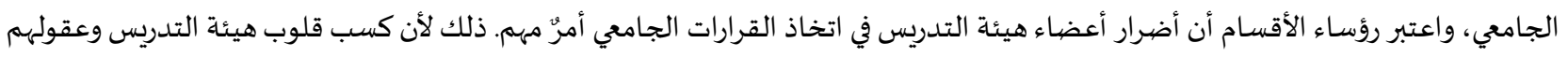
بالغ الأهمية لصالح التغيرات الضرورية إذا أرادت الجامعة أن تزدهر.

وحاول مارتن (Marten, 2001) في دراسته تحديد الدور الواقعي والمتوقع من رؤساء الأقسام من وجهة نظر عمداء كليات التربية في الأباما

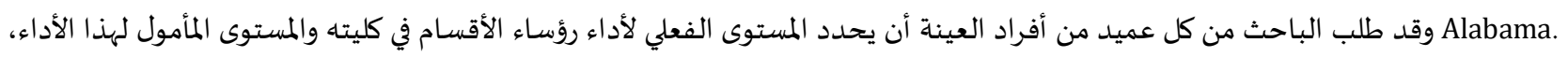

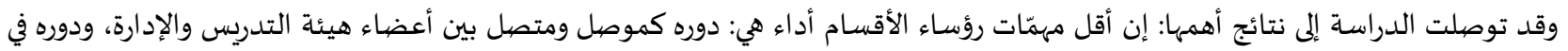

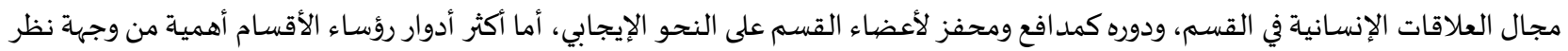

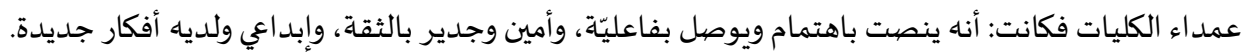

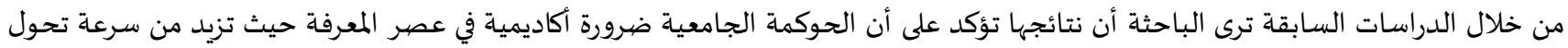

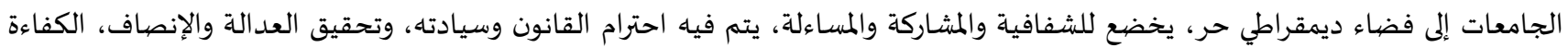
والفعالية، والاستخدام الأمثل للموارد والقدرات، مع القدرة على التعامل مع القضايا الملحة أو الأزمات. وتميزت الدراسة الحالية عن الدراسات السابقة

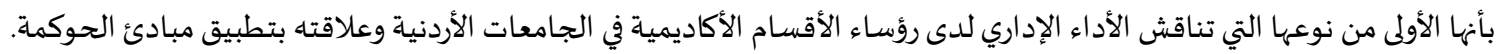

منهجية الدراسـة: استخدمت الباحثة المنهج الوصفي المستي، وهو منهج قائم على مجموعة من الإجراءات البحثيَّة التِّي تعتمد على جمع الحقائق والبيانات،

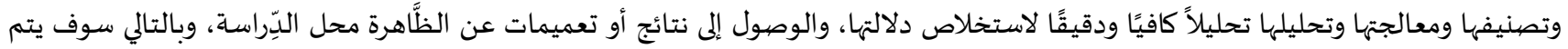

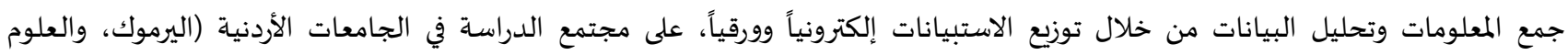
والتكنولوجيا، وآل البيت، وإربد الأهلية، وجدارا)، بحيث تشمل أعضاء الهيئة التدريسية في الأقسام الأكاديمية. مجتمع وعينة الدراسـة:

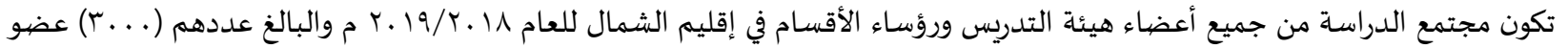

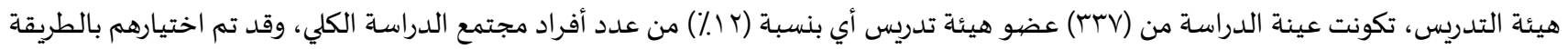

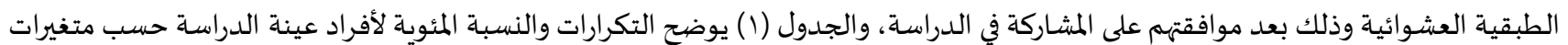

جدول (1): التكرارات والنسب المئوية حسب متغيرات الدراسة

\begin{tabular}{|c|c|c|c|}
\hline النسبة & التكرار & الفئات & المتغير \\
\hline 79,8 & rro & ذكر & الجنس \\
\hline$r \cdot, r$ & $1 . r$ & أنثى & \\
\hline$r 7, \varepsilon$ & 19 & •r- اقل من •؛ سنة & العمر \\
\hline$V r, r$ & $r \varepsilon \wedge$ & .عسنة فاكثر . & \\
\hline$r r, \varepsilon$ & 19 & أستاذ مساعد & الرتبة الأكاديمية \\
\hline$r_{.},$. & 1.1 & أستاذ مشارك & \\
\hline$\varepsilon 7,7$ & $10 \mathrm{~V}$ & أستاذ & \\
\hline$V r,$. & $r \leq 7$ & حكومية & الجامعة \\
\hline$r V,$. & 91 & خاصة & \\
\hline $77, \wedge$ & Tro & علمية & نوع الكلية \\
\hline$r r, r$ & 114 & إنسانية & \\
\hline$\varepsilon 9$, & 170 & اقل من · ا سنوات & مدة الخدمة \\
\hline $01,$. & IVT & ـ ا سنوات فاكثر & \\
\hline $1 \ldots$, & $r T r$ & المجموع & \\
\hline
\end{tabular}


قامت الباحثة ببناء استبانة للتعرف إلى واقع الأداء الإداري للأقسام الأكاديمية بالجامعات الأردنية في ضوء مبادئ الحوكمة من وجهة نظر أعضياء

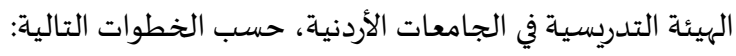

مراجعة الأدب التربوي الخاص بالحوكمة، والاطلاع على الدراسات السابقة ذات العلاقة.

تحديد مجالات الأداة والتي تكونت من قسمين: القسم الأول استبانة (واقع الأداء الإداري) وتكون من ستة محاور موزعة كما يلي (التخطيط

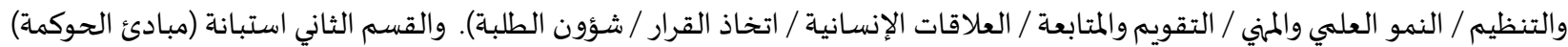
والذي تكون من أربعة محاور موزعة كما يلي (الشفافية / المشاركة / الفاعلية والكفاءة / التنافسية). صياغة عدد من الفقرات تحت كل مجال من مجالات الأداة، وقد بلغ عدد الفقرات (ال7) فقرة.

صددق أداة الدراسة:

للتأكد من الصيدق المنطقي ومجالاتها؛ تم عرضها في صورتها الأولية على مجموعة مؤلفة من (. ( ) محكمين من ذوي الخبرة والاختصاص في مجال الإدارة وأصول التربية، والمناهج وأساليب التدريس من العاملين في جامعة اليرموك، والجامعة الهاشمية، وجامعة آل البيت، حيث طلب منهم إبداء

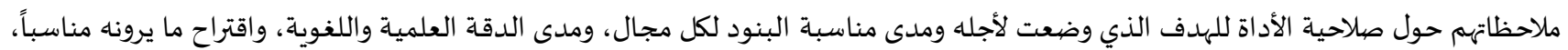

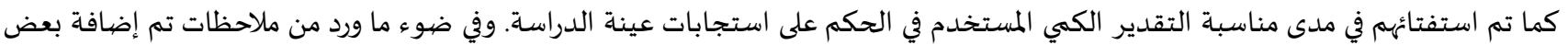
الفقرات، ودمج البعض الآخر، وحذف بعضهيها، وتعديل البعض من الآخر.

ثبات الأداة:

للتأكد من ثبات أداة الدراسة تم التأكد والتحقق من ثباهها عن طريق استخراج معامل الثبات كرونباخ ألفا.

المعيار الإحصيائي:

تم اعتماد سلم ليكرت الخماسي (Likert-Five-Scale) لتصحيح أدوات الدراسة، بإعطاء كل فقرة من فقراته درجة واحدة من داردة بين درجاته

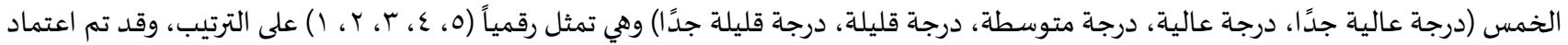

\begin{tabular}{|c|c|}
\hline قليلة & من . \\
\hline متوسطة & من عَr,r - \\
\hline كبيرة & من شך, - . . ,0 \\
\hline
\end{tabular}
وهكذا

وقد تم احتساب المقياس من خلال استخدام المعادلة التالية: الحد الأعلى للمقياس (0) - الحد الأدنى للمقياس (1) إسناسل

عدد الفئات المطلوبة (r)

$$
\frac{1, r r=1-0}{r}
$$

ومن ثم إضافة الجواب (rr, 1) إلى نهاية كل فئة. صدق البناء: و اقع الأداء الإداري

لاستخراج دلالات صدق البناء للمقياس، استخرجت معاملات ارتباط فقرات الإدات المقياس مع الدرجة الكلية في عينة استطلاعياة من خارج عينة الدراسة تكونت من (.ـ)، حيث تم تحليل فقرات المقياس وحساب معامل ارتباط كل فقرة من الفقرات، حيث أن معامل الارتباط هنا يمثل دلالة

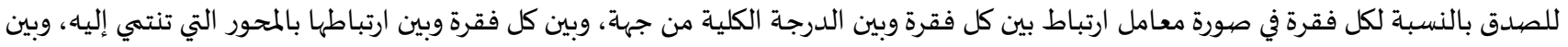

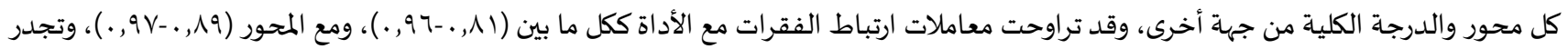

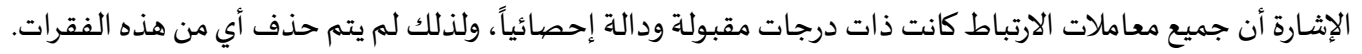


ثبات أداة الدراسـة: و اقع الأداء الإداري

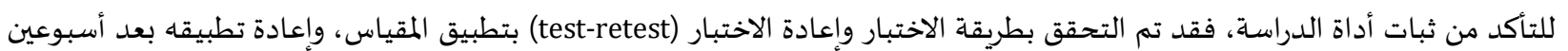
على مجموعة من خارج عينة الدراسة مكوّنة من (.ب)، ومن ثم تم حساب معامل ارتباط بيرسون بين تقديراتهم في المرتين.

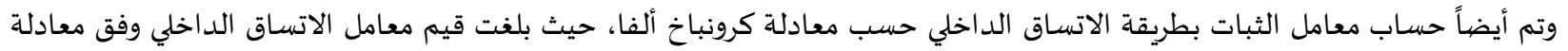

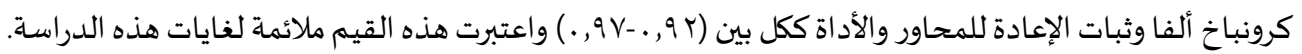
صيدق البناء: مبادئ الحوكمة لاستخراج دلالات صددق البناء للمقياس، استخرجت معاملات ارتباط فقرات المقياس مع الدرجة الكلية في عينة استطلاعية من خارج عينة الدراسة تكونت من (•ع)، حيث تم تحليل فقرات المقياس وحساب معامل ارتباط كل فقرة من الفقرات، لمقات حيث أن أن معامل الارتباط هنا يمثل دلالة

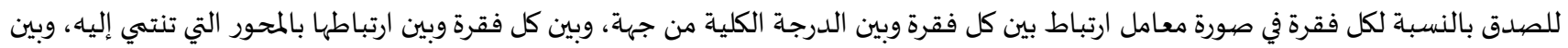

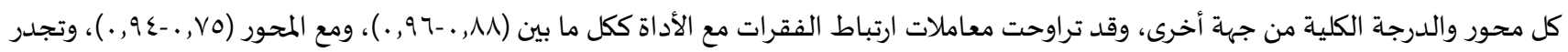

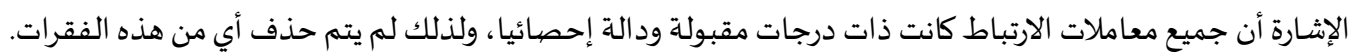

ثبات أداة الدراسـة: مبادئ الحوكمة جمانة للتأكد من ثبات أداة الدراسـة، فقد تم التحقق بطوريقة الاختبار وإعادة الاختبار (test-retest) بتطبيق المقياس، وإعادة تطبيقه بعد أسبوعين على مجموعة من خارج عينة الدراسة مكوّنة من (.ع)، ومن ثم تم حساب معامل ارتباط بيرسون بين تقديراتهم في المرتين.

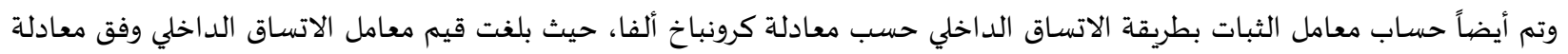

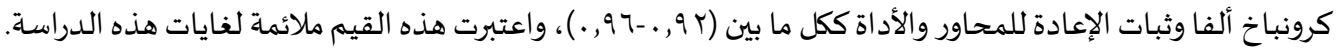

عرض ومناقشـة نتائج الدراسة

السؤال الأول: ماو اقع الأداء الإداري لدى رؤساء الأقسام الأكاديمية في الجامعات الأردنية الحكومية من وجهة نظر أعضياء هيئة التدريس؟

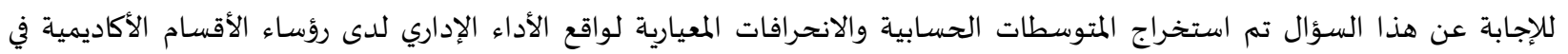
الجامعات الأردنية الحكومية من وجهة نظر أعضياء هيئة التدريس، والجدول أدناه يوضيح ذلك. جدول (r): المتوسطات الحسابية والانحر افات المعيارية لو اقع الأداء الإداري لدى رؤساء الأقسام الأكاديمية في الجامعات الأردنية الحكومية من وجهة نظر

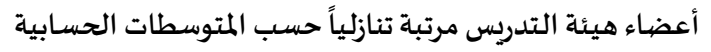

\begin{tabular}{|c|c|c|c|c|c|}
\hline المستوى & الانحراف المعياري & المتوسط الحسابي & المحور & الرقم & الرتبة \\
\hline متوسط &., 90 & $r, \varepsilon V$ & التخطيط والتنظيم & 1 & 1 \\
\hline متوسط & I,.rY & $r, r$. & النمو العلمي والمهني & r & r \\
\hline متوسط & $1, .0 r$ & $r, 1 \Lambda$ & التقويم والمتابعة & $r$ & $r$ \\
\hline متوسط & $1, . v V$ & $r, 10$ & العلاقات الإنسانية & $\varepsilon$ & $\varepsilon$ \\
\hline متوسط & $1, .09$ & $r, 1 \varepsilon$ & |تخاذ القرار & 0 & 0 \\
\hline متوسط & $1, .99$ & $r, 99$ & شؤون الطلبة & 7 & 7 \\
\hline متوسط &., $90 r$ & $r, r_{1}$ & واقع الأداء الإداري & & \\
\hline
\end{tabular}

يبين الجدول (r) أن واقع الأداء الإداري لدى رؤساء الأقسام الأكاديمية في الجامعات الأردنية الحكومية من وجهة نظر أعضاء هيئة التدريس جاء

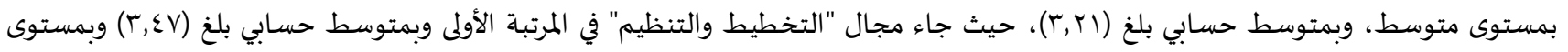

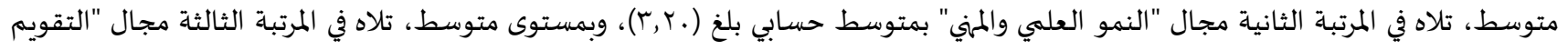

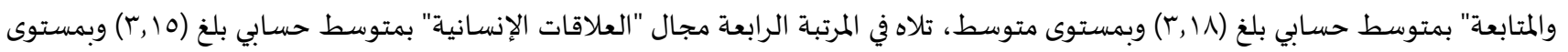

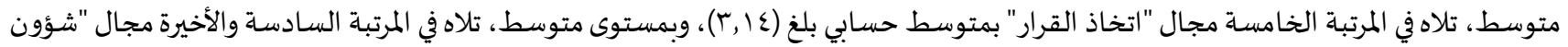

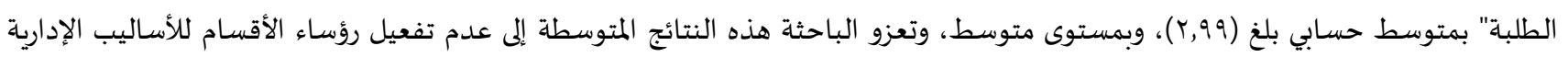

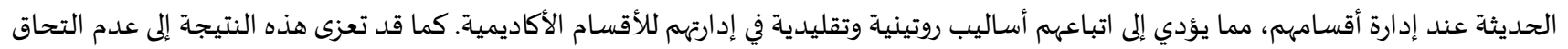

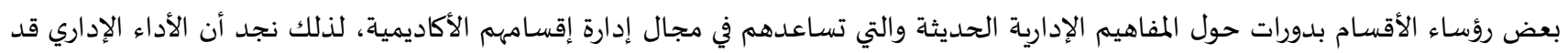

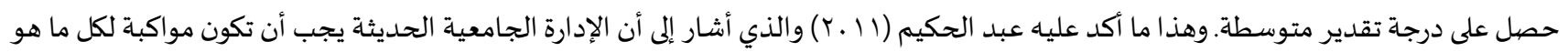


جديد من الأساليب الإدارية الحديثة التي تحقق رسالتها وأهدافها، خاصة في ظل تطورات هذا العصر الذي اتسم بعصر التطورات والتغيرات والتحديات السريعة والمستمرة.

واختلفت هذه النتيجة مع دراسة نجم (V ا _ التي أشـارت إلى أهمية امتلاك مهارات التخطيط والتنظيم والتنسيق والقيادة والتوجياء والرقابة

وتقييم الأداء بلدرجة عالية. وقد تم حساب المتوسطات الحسابية والانحرافات المعيارية لتقديرات أفراد عينة الدراسة على فقرات كل محور على حدة، حيث كانت على النحو

المحور الأول: التخطيط والتنظيم جدول (r): المتوسطات الحسابية والانحر افات المعيارية المتعلقة بالتخطيط والتنظيم مرتبة تنازلياً حسب المتوسطات الحسابية

\begin{tabular}{|c|c|c|c|c|c|}
\hline المستوى & 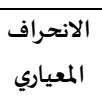 & الحتوسط الحسب & الفقرات & 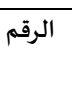 & الرتبة \\
\hline مرتفع & $1, \ldots 7$ & $r, v 1$ & الدراسات داخل القسم القدرة خارجه. الإشراف الأكاديمي و العلمي على البحوث و & 1 & 1 \\
\hline متوسط &., $90 \mathrm{r}$. & $r, O V$ & و أهمدافها التربوية. القسم على وضع خطة للقسم في ضوء السياسة العامة للجامعة & $r$ & $r$ \\
\hline متوسط & $1, . \wedge \varepsilon$ & $r, o v$ & القوانين الجامعيس القسم المعرفة و الدراية التامة باللوائح التنظيمية و التعليمات و & $r$ & $r$ \\
\hline متوسط & $1, .17$ & $r, \varepsilon V$ & الفصلية و يناقشها معهم. & $\varepsilon$ & $\varepsilon$ \\
\hline متوسط & $1,11 \varepsilon$ & $r, r_{\Lambda}$ & لدي البشئ و المادية. القسم القدرة على التنبؤ باحتياجات القسم الفعلية في الإمكانات & 0 & 0 \\
\hline متوسط & $1, .1$. & $r, r \varepsilon$ & يمتلك رئيس القسم القدرة و المهارة لإعداد خطة إدارية مادية لتحقيق & 7 & 7 \\
\hline متوسط & $1, .90$ & $r, r \Lambda$ & يعمل رئيس القسم على وضع خطة مرنة في قسمه لتطوير الخطط و المناهج & v & v \\
\hline متوسط &., 90 & $r, \varepsilon V$ & التخطيط والتنظيم & & \\
\hline
\end{tabular}

يبين الجدول (r) أن محور "التخطيط والتنظيم" قد جاء في المرتبة الأولى بمتوسط حسابي بلغ (عا,Y)، وبمستوى متوسط، كما تراوحت

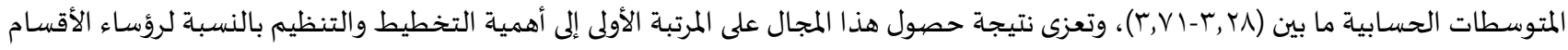

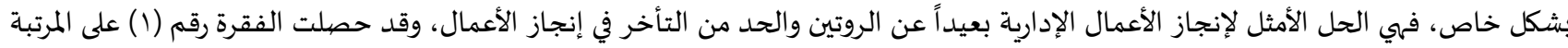

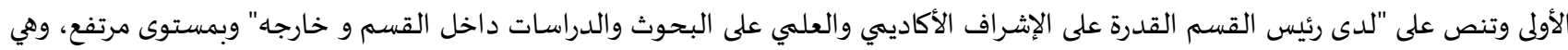
الفقرة الوحيدة التي حصلت على درجة تقدير مرتفعة، وتعزو الباحثة هذه النتيجة إلى الكفاءة العالية لرؤساء الأقسام في الجامعات الأردنية في مجال

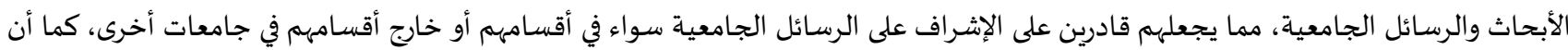

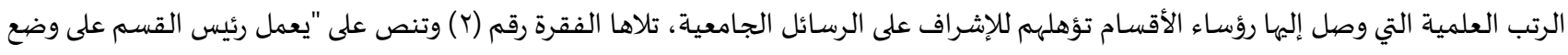

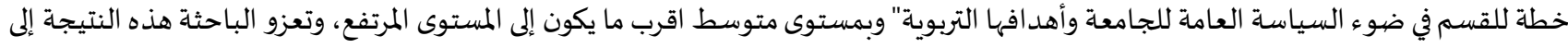

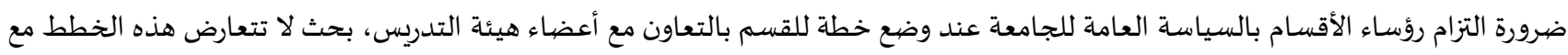

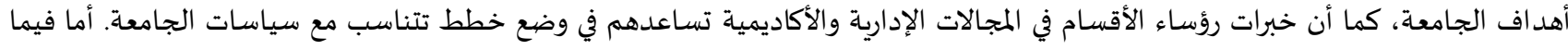

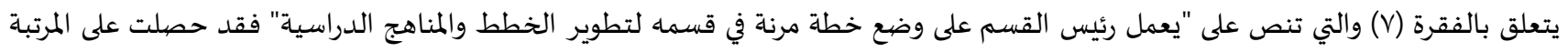
الأخيرة وبمستوى متوسط، وتعزو الباحثة حصول هذه الفقرة على المرتبة الأخيرة إلى الحرية التي يمتلكها أعضياء هيئة التدريس في اعتماد المناهج التي

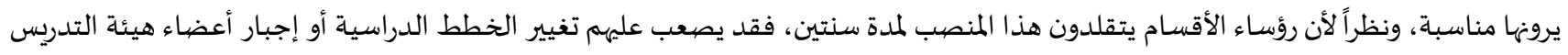
على اختيار مناهج دراسية جديدة. 
المحور الثاني: النمو العلمي والمهني

جدول (ع): المتوسطات الحسابية والانحر افات المعيارية المتعلقة بالنمو العلمي والمهني مرتبة تنازلياً حسب المتوسطات الحسابية

\begin{tabular}{|c|c|c|c|c|c|}
\hline المستوى & المعياري - الانحراف & الحسبابي & الفقرات & الرقم & الرتبة \\
\hline متوسط & $1, . \leqslant 0$ & $r, r$. & يناقش رئيس القسم أعضياء هيئة التدريس بالمقترحات و المتغيرات المتعلقة في & 7 & 1 \\
\hline متوسط & $1, .10$ & $r, r q$ & و يحرص رئيس الدسم على مشـاركة أعضاء هيئة التدريس في المؤتمرات و الندوات & 0 & $r$ \\
\hline متوسط & $1, .99$ & $r, r)$ & ي يدعم رئيس القسم مكتبة القسم بأحدث الرسائل و الأطاريح و المراجع و المجلات & $\mathrm{v}$ & $r$ \\
\hline متوسط & $1,1 T A$ & $r, 19$ & السابقة لزئيس القسم أعضاء الهيئة التدريسية الجدد من الإفادة من الخبرات & 1 & $\varepsilon$ \\
\hline متوسط & $1,10 \mathrm{~V}$ & r,IV & يعمل رئيس القسم على توفير إمكانيات البحث العلمي من أجل الحصيول على & $r$ & 0 \\
\hline متوسط & $1,1 \times 0$ & $r, i r$ & يحرص رئيس القسم على استغلال فرص النمو العلمي و المهني لأعضاء هيئة & $\varepsilon$ & 7 \\
\hline متوسط & 1,107 & $r, i r$ & يحفز رئيس القسم حركة البحث العلمي و التأليف و الترجمة بين أعضاء هيئة & $r$ & $\mathrm{v}$ \\
\hline & I,.TY & $r, r$. & النمو العلمي والمهني & & \\
\hline
\end{tabular}

يبين الجدول (ع) أن محور النمو العلمي والمهني قد جاء في المرتبة الثانية بمتوسط حسابي بلغ (.r,Y) وبمستوى متوسط، وهذه النتيجة المتوسطة

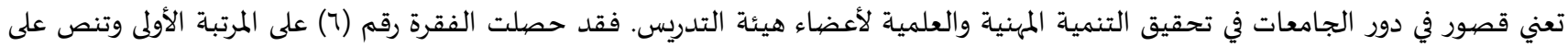
"يناقش رئيس القسم أعضاء هيئة التدريس بالمقترحات والمتغيرات المتعلقة في تطوير المناهج وتحديثها" وبمستوى متوسط، وتعزيه وتهزو الباحثة هذه النتيجة المتوسطة إلى أن رئيس القسم يجتمع في بداية كل فصل دراسي مع أعضاء هيئة التدريس لمناقشة الخطة الدراسية والمناهج، إلّا أن أعضاء هيئة التدريس لديهم الحرية في اختيار الكتب التي يودون استخدامها كمنهاج للمادة التي سيدرسونها، وقد يستمر عضيو هيئة التدريس في استخدام نفس المنهاج لسنوات عديدة إذا لاحظ فائدته، تلاها الفقرة رقم (0) وتنص على "يحرص رئيس القسم على مشاركة أعضياء هيئة التدريس في المؤتمرات والندوات والدورات التدريبية" وبمستوى متوسط، وتعزو الباحثة هذه النتيجة إلى أن رؤساء الأقسام يعملون على إعلام أعضياء هيئة التدريس بأبرز المستجدات حول المؤتمرات والندوات والدورات التدريبية، ويتركون لأعضاء هيئة التدريس الحرية في المشاركة فهها أم لا، أما فيما يتعلق بالفقرة (؟) والتي

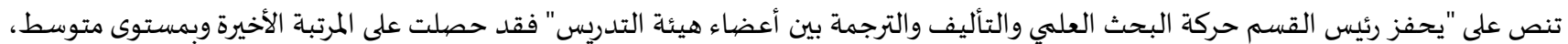
وهذه النتيجة تشير إلى قصور دور رؤساء الأقسام في تحسين مستوى البحث العلمي والتأليف والترجمة لأعضاء هيئة التدريس، إذ أن نموهم العلمي

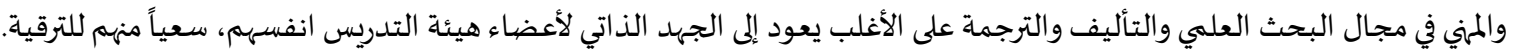
المحور الثالث: التقويم والمتابعة جدول (0): المتوسطات الحسابية والانحر افات المعيارية المتعلقة بالتقويم والمتابعة مرتبة تنازلياً حسب المتوسطات الحسابية

\begin{tabular}{|c|c|c|c|c|c|}
\hline 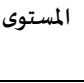 & 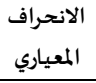 & الحسابي & 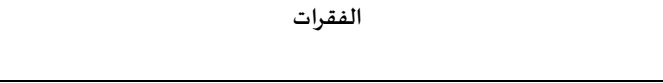 & 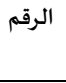 & 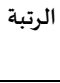 \\
\hline متوسط & $1,1 \% 1$ & $r, r q$ & يتابع رئيس القسم تنفيذ الخطط الأعمال التربوية و التعليمية لأعضاء هيئة & 1 & 1 \\
\hline متوسط & $1,17 \mathrm{~V}$ & $r, 11$ & يتابع رئيس القسم بانتظام سير المهام التعليمية و البحثية في قسمه. & $\circ$ & $r$ \\
\hline متوسط & 1,174 & $r, I V$ & اليُطلح رئيس القسم أعضاء هيئة التدريس على نتائج تقييم أدائهم الأكاديمي و & $r$ & $r$ \\
\hline متوسط & $1,10 \mathrm{r}$ & $r, 17$ & يعتمد رئيس القسم على المعايير الدقيقة و الموضوعية و ضوابط العمل في تقويم & r & $\varepsilon$ \\
\hline متوسط & 1,171 & $r, 10$ & للطلبة في قسيس القسم الوسائل و المعايير الحديثة و تقويم التحصيل المعرفي & $\varepsilon$ & 0 \\
\hline متوسط & 1,.or & $r, 11$ & التقويم والممتابعة & & \\
\hline
\end{tabular}

يبين الجدول (0) أن محور "التقويم والمتابعة" قد جاء في المرتبة الثالثة بمتوسط حسابي (ب,|^) وبمستوى متوسط، فقد حصلت الفقرة رقم (1)

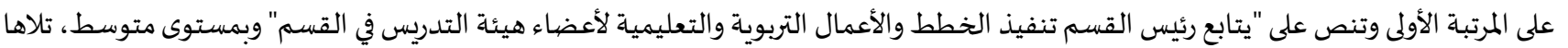
الفقرة رقم (0) وتنص على "يتابع رئيس القسم بانتظام سير المهام التعليمية والبحثية في قسماه، وتعزو الباحثة هذه النتيجة المتوسطة إلى انشغال 
رؤساء الأقسام بالأعمال الإدارية والأكاديمياة، إذا يتوجب عليهم إعطاء مساقات عدة، والقيام بواجبات رئيس القسم كإداري، لذلك فإنها لا يتسنى لهم

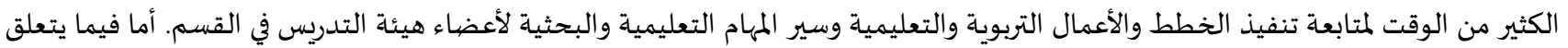
بالفقرة (ع) والتي تنص على "يوظف رئيس القسم الوسائل والمعايير الحديثة وتقويم التحصيل المعرفي للطلبة في قسماه" فقد حصلت على المرتبة الأخيرة

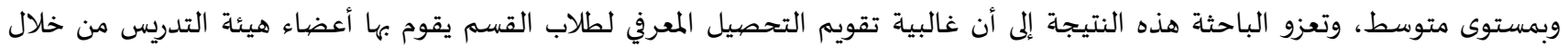

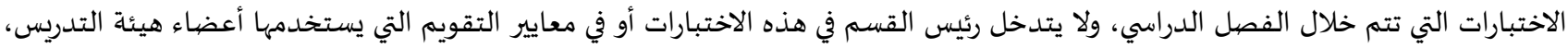

وهذه النتائج تشير إلى وجود ضعف لدى رؤساء الأقسام في استخدام معايير واضحة لتقويم أداء الطلبة وأعضاء الهاء الهيئة التدريسية، وتقويم الخطط. المحور الر ابع: العلاقات الإنسانية جدول (7): المتوسطات الحسابية والانحر افات المعيارية المتعلقة بالعلاقات الإنسانية مرتبة تنازلياً حسب المتوسطات الحسابية

\begin{tabular}{|c|c|c|c|c|c|}
\hline المستوى & 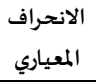 & الحتوسط الحسبي & الفقرات & الرقم & الرتبة \\
\hline متوسط & $1,1 \mathrm{VV}$ & $r, 19$ & بين أعضاء رئيس القسم إلى خلق جو يسوده التعاون و المحبة و الاحترام و الانسجام & $r$ & 1 \\
\hline متوسط & 1,179 & $r, I V$ & الكلية و الجامعة. & $\varepsilon$ & $r$ \\
\hline متوسط & 1,170 & $r, 17$ & القسم. رئيس القسم على السمعة الأكاديمية الجيدة لأعضاء هيئة التدريس في & 0 & $r$ \\
\hline متوسط & $1,1 \leqslant r$ & $r, 10$ & و الطبنى فئيس القسم الأسلوب الديمقراطي في التعامل مع أعضاء الهيئة التدريسية & 7 & $\varepsilon$ \\
\hline متوسط & I,TYY & $r, 1 \varepsilon$ & متسلطًا عليهم. ئسم أعضاء هيئة التدرس و العاملين معاه بأنه جزء منهم و ليس & 1 & 0 \\
\hline متوسط & $1, I V r$ & r,IT & التدربس في القسم. & $r$ & 7 \\
\hline متوسط & $1, \cdot v V$ & $r, 10$ & العلاقات الإنسانية & & \\
\hline
\end{tabular}

يبين الجدول (7) أن محور "العلاقات الإنسانية" جاء في المرتبة الرابعة بمتوسط حسابي (r,10) وبمستوى متوسط، فقد حصلت الفقرة رقم (r) على المرتبة الأولى وتنص على "يسعى رئيس القسم إلى خلق جو يسوده التعاون والمحبة والاحترام والانسجام بين أعضاء هيئة التدريس في القسم"

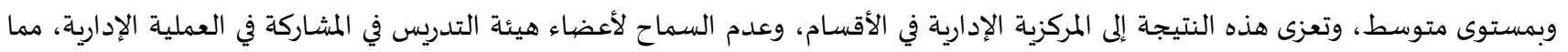
يخلق جوا من عدم التآلف بين رؤساء الأقسام وأعضاء هيئة التدريس. أما فيما يتعلق بالفقرة (r) والتي تنص على "يتسم تعامل رئيس القسم بالعدالة

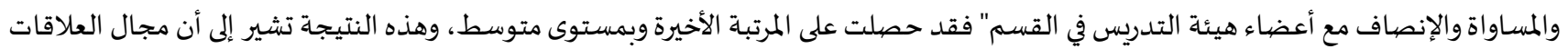

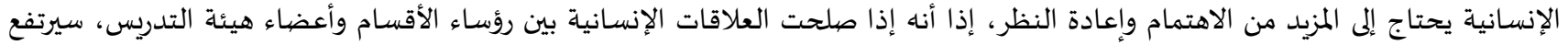
مستوى الأداء الإداري بشكل عام، حيث سيشارك أعضاء هيئة التدريس في عمليات التخطيط والتنظيم واتخاذ القرارات ويساعدون رئيس القسم على إلى إلى أداء وظائفه ونقل القسم إلى مستوى عالي من الإنجاز. المحور الخامس: اتخاذ القرار جدول (V): المتوسطات الحسابية والانحر افات المعيارية المتعلقة باتخاذ القرار مرتبة تنازلياً حسب المتوسطات الحسابية

\begin{tabular}{|c|c|c|c|c|c|}
\hline 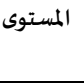 & 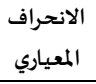 & الحسبط المتوسط & 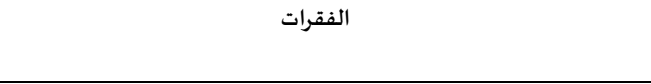 & 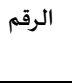 & الرتبة \\
\hline متوسط & $1,1 \varepsilon \wedge$ & $r, r r$ & يعتمد رئيس القسم على الأساس العلمية في صنع و اتخاذ القرارات الإدارية على & r & 1 \\
\hline متوسط & 1,1 1, & $r, 11$ & مشاور القضسم. هيئة التدريس في القرارات قبل اتخاذها و بالشكل الأفضل مراعيًا & 1 & $r$ \\
\hline متوسط & 1,101 & $r, 10$ & القرارات الإدارية على مستوى القسي علىمهر المعلومات الكافية التي تساعد على اتخاذ & $r$ & $r$ \\
\hline متوسط & 1,141 & $r, 1$. & وضنفة رئيس القسم قرارات و توصيات مجالس القسم و الكلية و الجامعة بدقة و & $\varepsilon$ & $\varepsilon$ \\
\hline 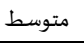 & $1,11$. & $r, \cdot r 3$ & يعتمد رئيس القسم على أسلوب البديل الأفضل من بين البدائل المقترحة & $\circ$ & $\circ$ \\
\hline متوسط & $1, .09$ & $r, 1 \varepsilon$ & اتخاذ القرار & & \\
\hline
\end{tabular}

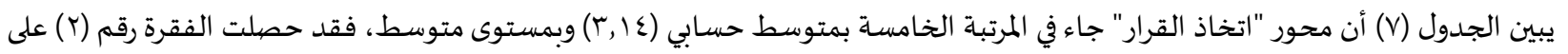
المرتبة الأولى وتنص على "يعتمد رئيس القسم على الأسس العلمية في صنع واتخاذ القرارات الإدارية على مستوى القسم" وبمستوى متوسط، وتهرئ وتعزو 
الباحثة هذه النتيجة المتوسطة إلى أن عملية اتخاذ القرارات بأسلوب علمي تحتاج إلى أن يكون متخذ القرار قد خضع لدورات تدريبية في المجالات

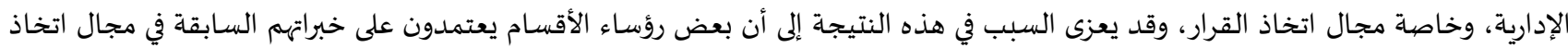

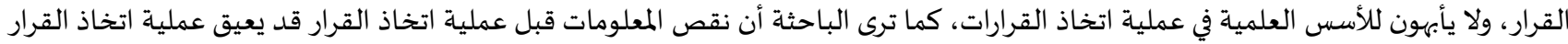

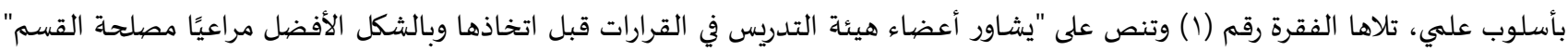

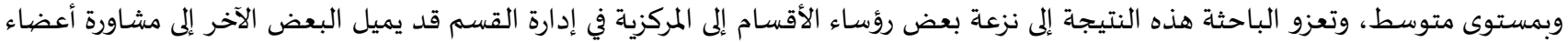

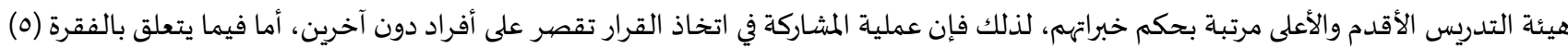

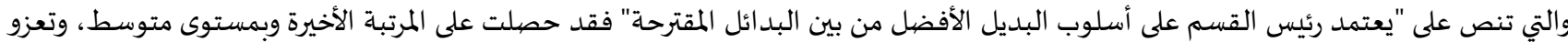

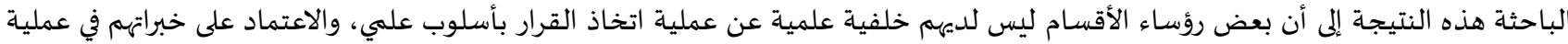

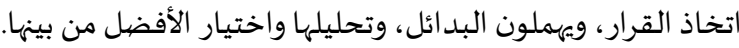

المحور السادس: شؤون الطلبة

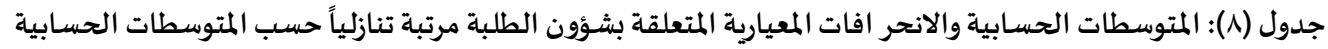

\begin{tabular}{|c|c|c|c|c|c|}
\hline 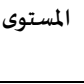 & 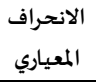 & الحسبط المتوسط & 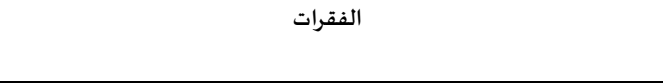 & 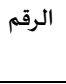 & الرتبة \\
\hline متوسط & $1, r \cdot 1$ & $r, . r$ & يشرف رئيس القسم على إعدادو حفظ السجلات الأكاديمية لطلبة القسم و & r & 1 \\
\hline متوسط & 1,191 & $r, .1$ & لدى رئيس القسم إلمام بنظام القبول و التسجيل في الجامعة. & r & r \\
\hline متوسط & $1, Y \xi Y$ & $r, .1$ & يرشيا رئيس القسم الطلبة المتميزين علميًا للتعيين و الدراسة في برنامج الدراسات & $\varepsilon$ & $r$ \\
\hline 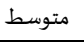 & 1,174 & $r, 9 \vee$ & يعالج رئيس القسم مشكلات الطلبة الدراسية و الاجتماعية & 1 & $\varepsilon$ \\
\hline متوسط & 1,174 & r,97 & يعمل رئيس القسم على إجراء مقابلة للطلبة الجدد و يطلعهم على سياسة & $\circ$ & $\circ$ \\
\hline متوسط & $1, .99$ & $r, 99$ & شؤون الطلبة & & \\
\hline
\end{tabular}

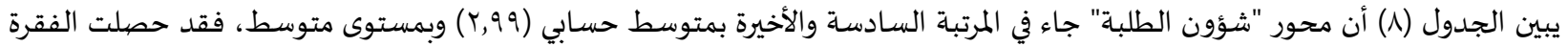

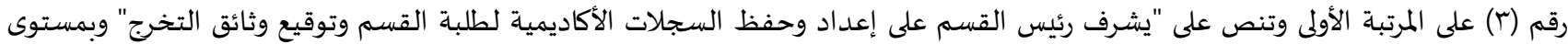

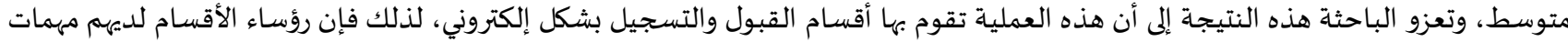

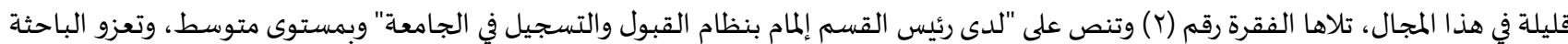

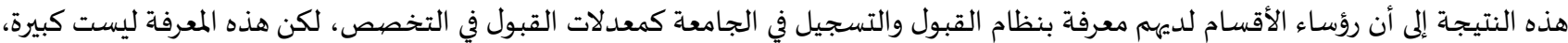
لأن شؤون القبول ولتسجيل معنية بالإدارة الجامعية ودائرة القبول والتسجيل، أما فيما يتعلق بالفقرة (0) والتي تنص على "يعمل رئيس القسم على لئل إجراء مقابلة للطلبة الجدد ويطلعهم على سياسة القسم" فقد حصلت على المرتبة الأخيرة وبمستوى متوسط، وهذه النقاذ النتيجة تشير إلى قصور دور رؤساء

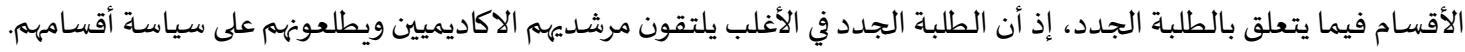

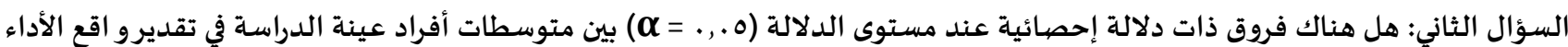

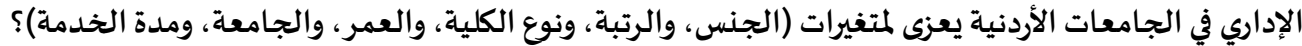

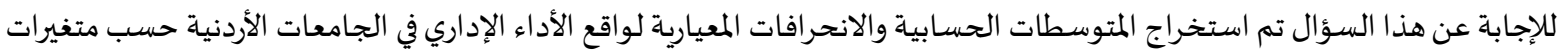

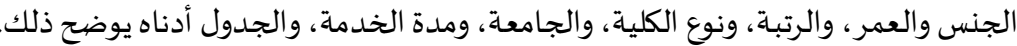
جدول (9): المتوسطات الحسابية والانحر افات المعيارية لو اقع الأداء الإداري في الجامعات الأردنية حسب متغيرات الجات الجاديات الجنس والعمر ، والرتبة، ونوع الكلية، والجـامعة، ومدة الخدمة

\begin{tabular}{|c|c|c|c|c|c|c|c|c|c|}
\hline و اقع الأداء & شؤون الطلبة & اتخاذ القرار & العالإقساتية & والمتابعة & النمو العلمي & والتخطيط & & & \\
\hline r, & $r, 11$ & r, ro & $r, r \Lambda$ & r, rA & r, ro & $r, 7$. & س س & ذكر & الجنس \\
\hline., $91 \mathrm{r}$ & $1, .09$ & $1, \ldots v$ & $1, . r$. & $1, . r r$ & •,99६ &., 940 & $\varepsilon$ & & \\
\hline$r, q r$ & $r, V \varepsilon$ & r,A & T,AT & $r, 97$ & $r, 10$ & $r, 1 \Lambda$ & س س & \multirow[t]{2}{*}{ أنثى } & \\
\hline., 919 & 1,101 & $1,1 r \varepsilon$ & $1,1 \%$. & $1, .19$ & $1, .1$ & .,QTY & $\varepsilon$ & & \\
\hline r,rT & $r, 1$. & $r, r \varepsilon$ & $r, r \varepsilon$ & $r, r r$ & $r, r$. & $r, 07$ & س س & \multirow[t]{2}{*}{ • ץ- اقل من •ع سنة } & العمر \\
\hline., $9 \vee \varepsilon$ & $1, \cdot v \wedge$ & $1, .99$ & $1, .7$ & $1, . r o$ &., 991 & $1, \ldots 0$ & $\varepsilon$ & & \\
\hline$r, 17$ & $r, 97$ & $r, 1$. & $r, . q$ & r,IT & $r, 17$ & $r, \varepsilon 0$ & س س & ــ سنة فاكثر & \\
\hline
\end{tabular}




\begin{tabular}{|c|c|c|c|c|c|c|c|c|c|}
\hline$\cdot, 9 \leq \varepsilon$ & $1,1.7$ & $1, . \varepsilon \varepsilon$ & $1, . v \wedge$ & $1, .07$ & $1, . r 1$ & $\cdot, 9 r$. & $\varepsilon$ & & \\
\hline$r, r)$ & $r, . \wedge$ & r,tr & $r, r q$ & r,ir & T & $r, 07$ & س & \multirow[t]{2}{*}{ أستاذ مسـاعد } & \multirow[t]{3}{*}{ الرتبة الأكاديمية } \\
\hline (q人ץ & $1, . \wedge 1$ & $1, . \leqslant V$ & $1,1 \cdot V$ & $1, .0 \mathrm{~V}$ & $1, .+4$ & $\cdot, 979$ & $\varepsilon$ & & \\
\hline$r, 17$ & $r, 97$ & $r, .1$ & $r, .0$ & r,Ir & $r, 19$ & $r, \varepsilon\rceil$ & س س س & \multirow[t]{2}{*}{ أستاذ مشـارك } & \\
\hline$\cdot, 91 \varepsilon$ & $1, .+r 7$ & $1, .11$ & $1, . \leqslant 1$ & $\cdot, 9 \vee 9$ & $\cdot, 9 \leq r$ &., $9 \curlyvee \varepsilon$ & $\varepsilon$ & & \\
\hline$r, 1 \Lambda$ & $r, 9 \wedge$ & r,ir & $r, 10$ & $r, 10$ & $r, 1 \varepsilon$ & $r, \varepsilon \varepsilon$ & س س س & \multirow[t]{2}{*}{ أستاذ } & \\
\hline$\cdot, 97 \varepsilon$ & $1,1 \leqslant 1$ & $1, .0 \varepsilon$ & $1, .10$ & $1, .9 \mathrm{~V}$ & $1, .70$ &., 97. & $\varepsilon$ & & \\
\hline$r, . .1$ & $r, \lambda r$ & $r, 97$ & $r, 9 V$ & T,qV & $r, 99$ & $r, r q$ & س س & حكومية & الجامعة \\
\hline$\cdot, 901$ & $1,1 \% 0$ & $1, .0 \mathrm{~V}$ & $1, \cdot V T$ & $1, .7$ & $1, . \leqslant 1$ & (974 & $\varepsilon$ & & \\
\hline r,VT & $r, \varepsilon_{0}$ & $r, 71$ & $r, 70$ & $r, v$, & r,vo & $r, 99$ & س س س & \multirow[t]{2}{*}{ خاصة } & \\
\hline •, VYT & $\cdot, \wedge \varepsilon \vee$ & $\cdot, 911$ &., 94. & $\cdot, V \vee \varepsilon$ & , VYO & $\cdot, 791$ & $\varepsilon$ & & \\
\hline$r, 1$. & $r, \wedge 7$ & $r, .1$ & $r, .0$ & $r, 11$ & $r, .9$ & $r, r_{\Lambda}$ & س س & علمية & \multirow[t]{4}{*}{ نوع الكلية } \\
\hline $1, \ldots$ & $1,1 \leqslant 1$ & $1,1.9$ & $1,10 \varepsilon$ & $1,1 \cdot 1$ & $1, . \varepsilon$. & $\cdot, 97 \mathrm{~V}$ & $\varepsilon$ & & \\
\hline$r, \varepsilon 1$ & $r, r q$ & $r, r q$ & r, ro & r,tr & $r, \varepsilon 1$ & $r, 77$ & س س س & \multirow[t]{2}{*}{ إنسانية } & \\
\hline$\cdot, \Lambda 1 \mathrm{~V}$ &., $9 \leq 7$ & $\cdot, 9 \cdot r$ & .,AV7 &., $9 Y$. &., 907 & ., ८91. & $\varepsilon$ & & \\
\hline$r, 10$ & T, १६ & $r, . r$ & $r, .0$ & $r, 1 \varepsilon$ & $r, 19$ & $r, \varepsilon r$ & س س & \multirow[t]{2}{*}{ اقل من • ا سنوات } & \multirow[t]{2}{*}{ مدة الخدمة } \\
\hline - $90 \mathrm{r}$ & $1, .79$ & $1, \cdot v$. & $1, .71$ & $1, . \mathrm{TV}$ & $1, \ldots 0$ & $\cdot, 9 \leqslant 9$ & $\varepsilon$ & & \\
\hline$r, r\urcorner$ & $r, .0$ & $r, r)$ & r, ro & r,r & $r, r$. & $r, 01$ & س & \multirow[t]{2}{*}{ ـ ا سنوات فاكثر } & \\
\hline$\cdot, 90 \leqslant$ & $1,1 \mathrm{TV}$ & $1, . \leqslant 7$ & $1, .11$ & $1, . \vee \wedge$ & $1, . \varepsilon r$ & .,90r & $\varepsilon$ & & \\
\hline
\end{tabular}

س= المتوسط الحسابي ع=الانحراف المعياري

يبين الجدول (9) تبايناً ظاهرياً في المتوسطات الحسابية والانحرافات المعيارية لواقع الأداء الإداري في الجامعات الأردنية بسبب اختلاف فئات

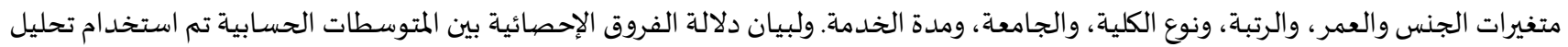

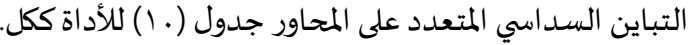

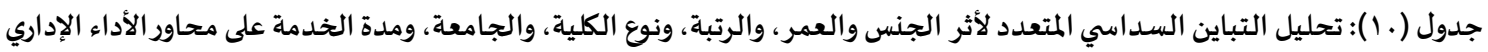

\begin{tabular}{|c|c|c|c|c|c|c|}
\hline الإحصبائية الدلالة & قيمة ف & متوسط المربعات & الحرية & مجموع المربعـات & المحاور & مصدر التباين \\
\hline$\ldots \wedge$ & V,rT. & $0,7 \vee 9$ & 1 & $0,7 \vee 9$ & التخطيط والتنظيم & الجنس \\
\hline.,$\ldots 1$ & $1 .$, Vqr & 9,107 & 1 & $9, \vee 07$ & النمو العلمي والمهني & هوتلنج= . 7 ., . \\
\hline., $10 \varepsilon$ & T,. rA & 1,910 & 1 & 1,910 & التقويم والمتابعة & $\ldots \varepsilon=\tau$ \\
\hline.,.$r$. & $\varepsilon, V Y Y$ & $\varepsilon, \Lambda \uparrow Y$ & 1 & $\varepsilon, \wedge \uparrow Y$ & العلاقات الإنسانية & \\
\hline., $.9 V$ & T,V70 & T,VרV & 1 & T,VTV & اتخاذ القرار & \\
\hline., .9 & $r, \wedge \wedge 9$ & $r, Y \cdot r$ & 1 & $r, r \cdot r$ & شؤون الطلبة & \\
\hline.,$\varepsilon \pi \mid$ & . TYK & $\cdot, \lambda \varepsilon 9$ & 1 & . ¿ะ८१. & التخطيط والتنظيم & العمر \\
\hline.,$Y V I$ & $1, r \backslash V$ & $1,1 \ldots$ & 1 & $1,1 \ldots$ & النمو العلمي والمهني & هوتلنج=0 ro ,. \\
\hline., $9 \varepsilon$. & $\ldots 7$ & $\ldots 7$ & 1 & $\ldots 7$ & التقويم والمتابعة &.,$r \varepsilon r=\tau$ \\
\hline$\cdot,\{7\}$ &., $0 \leqslant 7$ &., $00 \mathrm{~V}$ & 1 &., $00 \mathrm{~V}$ & العلاقات الإنسانية & \\
\hline$\cdot, \mathrm{VVI}$ &., .10 &., .10 & 1 &., .10 & اتخاذ القرار & \\
\hline$\cdot, 107$ & 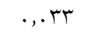 & .,.rד & 1 & .,.ru & شؤون الطلبة & \\
\hline., 149 & $r, .09$ & 1,711 & $r$ & r, rro & التخطيط والتنظيم & الرتبة الأكاديمية \\
\hline., 1 To & $r, .9 \varepsilon$ & 1,194 & r & r,v人ૉ & النمو العلمي والمهني & ويلكس= = 9VY, . \\
\hline., 510 & $1,0 \leqslant 7$ & $1,0 . V$ & $r$ & $r, .1 r$ & التقويم والمتابعة &.,$\lambda \wedge r=\tau$ \\
\hline., $.7 r$ & $r, \Lambda \cdot V$ & T,人77 & r & 0,VTr & العلاقات الإنسانية & \\
\hline., $.0 \mathrm{~V}$ & $r, \wedge 10$ & $r, \wedge \wedge \wedge$ & r & $0, \mathrm{~V} v 0$ & اتخاذ القرار & \\
\hline.,$Y \leqslant 7$ & $1, \varepsilon \cdot 9$ & $1,07 T$ & r & r,ITr & شؤون الطلبة & \\
\hline$\ldots$ & ro, roo & 19,149 & 1 & $19,1 / 9$ & التخطيط والتنظيم & الجامعة \\
\hline.,$\ldots$ & $r 0,091$ & rr,ITr & 1 & rT,ITr & النمو العلمي والممني & هوتلنج=1 • 1,. \\
\hline$\ldots$ & $r \cdot, r \varepsilon 1$ & $r q, \varepsilon 77$ & 1 & $r 9, \varepsilon 77$ & التقويم والمتابعة & $\cdots, \cdots=r$ \\
\hline.,$\ldots$ & $1 \varepsilon, \varepsilon 70$ & $1 \varepsilon, 179$ & 1 & $1 \varepsilon, 179$ & العلاقات الإنسانية & \\
\hline$\cdot, \ldots$ & $1 \varepsilon, 1 . r$ & $1 \varepsilon, 117$ & 1 & 18,117 & اتخاذ القرار & \\
\hline.,$\ldots 1$ & $11,10 \varepsilon$ & $|r| \leqslant 1$, & 1 & $|r| \leq 1$, & شؤون الطلبة & \\
\hline
\end{tabular}




\begin{tabular}{|c|c|c|c|c|c|c|}
\hline.,$T \backslash \Lambda$ & 1,040 & 1,191 & 1 & 1,191 & التخطيط والتنظيم & نوع الكلية \\
\hline., $1 \mathrm{VI}$ & $1,1 \vee 9$ & .1791 & 1 & 1,791 & النمو العلمي والمهني & هوتلنج= =r .,. \\
\hline . 700 & ., r. &., $19 \varepsilon$ & 1 &., $19 \varepsilon$ & التقويم والمتابعة &., $.71=\tau$ \\
\hline., 171 & $1,9.0$ & $1,9 \leqslant 7$ & 1 & $1,9 \leqslant 7$ & العلاقات الإنسانية & \\
\hline.,.$M T$ & O, YVY & $0, r V V$ & 1 & $0, \mathrm{TVV}$ & اتخاذ القرار & \\
\hline.,.$+Y$ & $0, \ldots 7$ & $0,0 \leqslant 9$ & 1 & $0,0 \leqslant 9$ & شؤون الطلبة & \\
\hline., .97 & r,VQT & $r, 19 r$ & 1 & r, 194 & التخطيط والتنظيم & مدة الخدمة \\
\hline . हाq & $.9 \mathrm{TV}$ &., $07 \mathrm{~V}$ & 1 &., $07 \mathrm{~V}$ & النمو العلهي والممني & 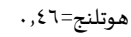 \\
\hline.,.$V r$ & T,YMT & $r, 1 \leqslant 9$ & 1 & $r, 1 \leq 9$ & التقويم والمتابعة &.,$. T r=\tau$ \\
\hline$\ldots r$ & $1, \vee r 9$ & $1,91 \%$ & 1 & 1,914 & العلاقات الإنسانية & \\
\hline$\ldots, \ldots 9$ & $7,19 \mathrm{~V}$ & $7,9 . \varepsilon$ & 1 & $7,9 \cdot \varepsilon$ & اتخاذ القرار & \\
\hline \multirow[t]{13}{*}{.,$\wedge r$} & $r, .19$ & $r, r \varepsilon v$ & 1 & $r, r \leqslant v$ & شؤون الطلبة & \\
\hline & &., V^४ & rTq & rON,£\&1 & التخطيط والتنظيم & الخطأ \\
\hline & &., $9 . \varepsilon$ & rTq & rqv, rqv & النمو العلمي والمنهي & \\
\hline & &., $9 \vee \varepsilon$ & rTq & $r r ., 077$ & التقويم والمتابعة & \\
\hline & & $1, \cdot Y 1$ & rTq & rTo,qr. & العلاقات الإنسانية & \\
\hline & & $1, \ldots 1$ & rTq & $r r q, r \cdot q$ & اتخاذ القرار & \\
\hline & & $1,1.9$ & rTq & $r Y \varepsilon, V \backslash \Lambda$ & شؤون الطلبة & \\
\hline & & & rru & $r \cdot r, r \cdot r$ & التخطيط والتنظيم & الكلي \\
\hline & & & $r+7$ & rol, ror & النمو العلهي والمهني & \\
\hline & & & rT & TVY,YTY & التقويم والمتابعة & \\
\hline & & & $r m$ & $r q ., . r r$ & العلاقات الإنسانية & \\
\hline & & & $r \mu$ & rуч,vq. & اتخاذ القرار & \\
\hline & & & TrM & $\varepsilon .0,90$. & شؤون الطلبة & \\
\hline
\end{tabular}

يتبين من الجدول (. (1) الآتي:

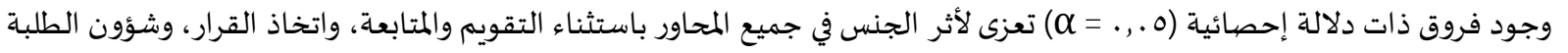

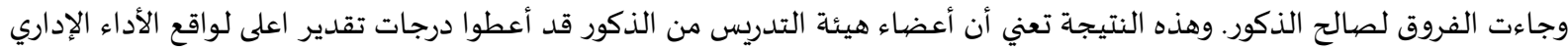

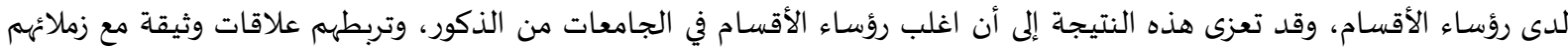

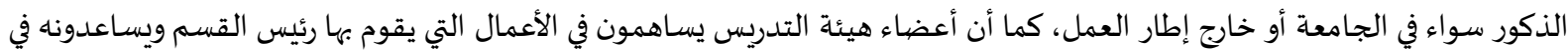
اتخاذ القرارات في معظم الأحيان، لذلك فقد أعطوا درجات تقدير أعلى لممارسة رؤساء الأقسام للأداء الإداري.

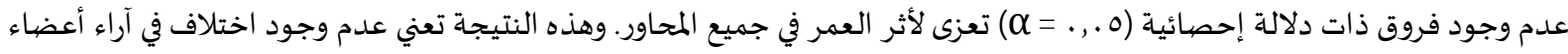

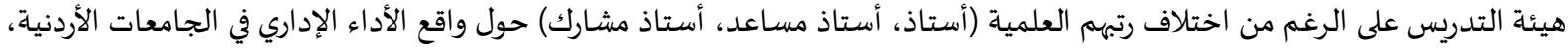

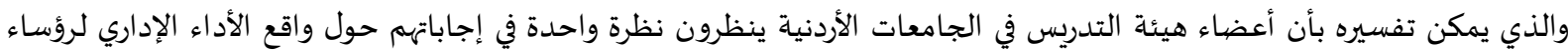

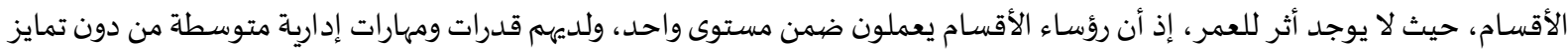
بينهم في الأداء الإداري.

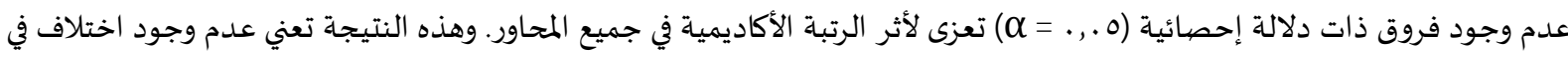

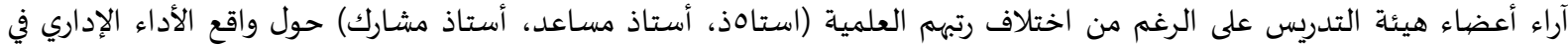

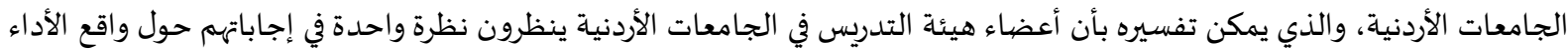

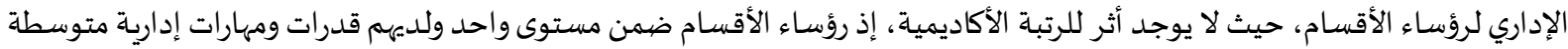
من دون تمايز بيههم في الأداء الإداري.

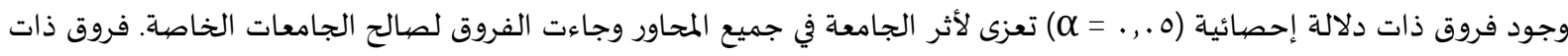

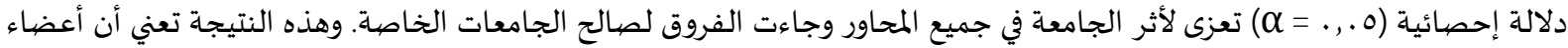

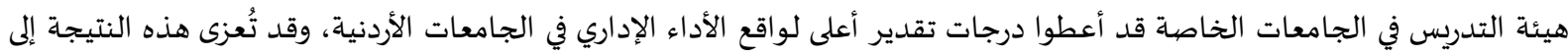

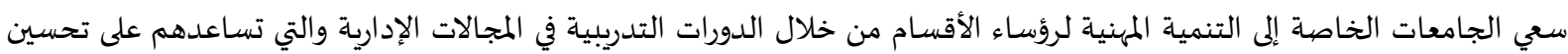

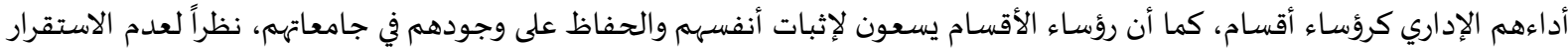

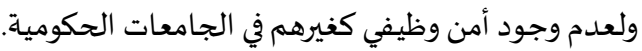


عدم وجود فروق ذات دلالة إحصائية (ه. . . = م) تعزى لأثر نوع الكلية في جميع المحاور باستثناء اتخاذ القرار، وشؤون الطلبة وجاءت

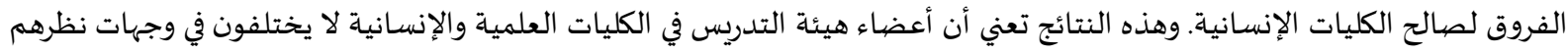

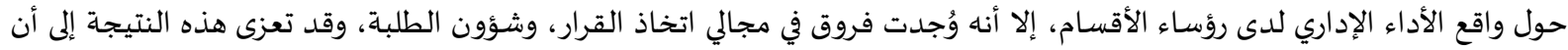

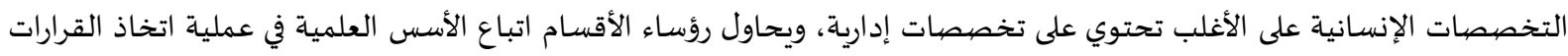
نظراً لخبراتهم في هذا المجال، كما أن رؤساء الأقسام في التخصصات الإنسانية لديهم علاقات وتواتيهات الإسل أكبر مع الطلبة، ولديهم إلمام أكبر بنظام ومعايير قبول الطلبة. عدم وجود فروق ذات دلالة إحصائية (ه.,. = $\alpha)$ تعزى لأثر مدة الخدمة في جميع المحاور باستثناء العلاقات الإنسانية، واتخاذ القرار

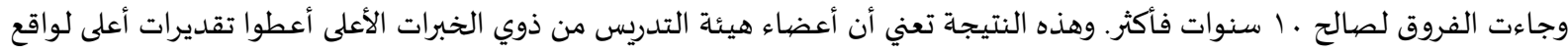

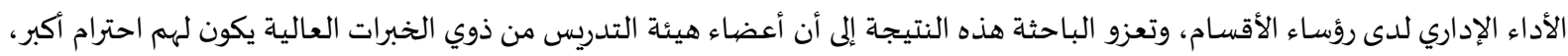

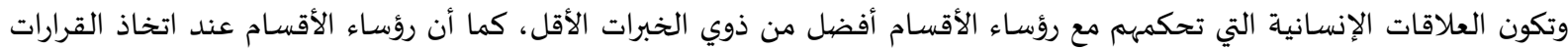
الإدارية بحكم خبراتهم في المجال الإداري والأكاديمي.

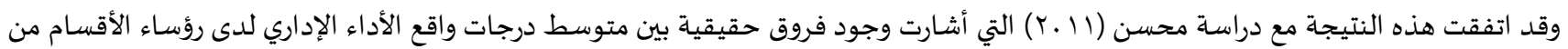

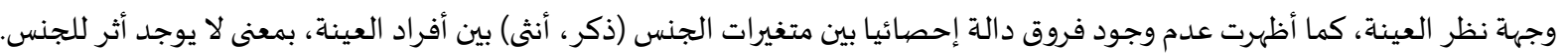

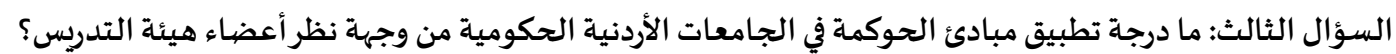

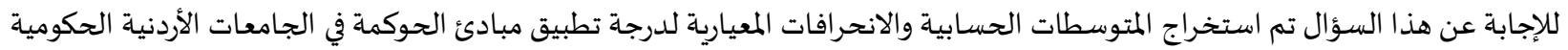
من وجهة نظر أعضاء هيئة التدريس، والجدول هذول أدناه يوضيح ذلك.

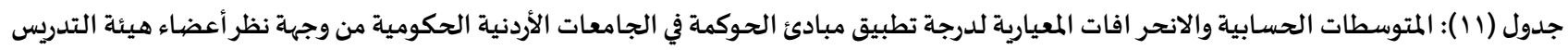

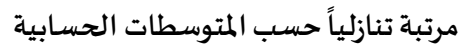

\begin{tabular}{|c|c|c|c|c|c|}
\hline المستوى & الانحراف المعياري & المتوسط الحسابي & المحور & الرقم & الرتبة \\
\hline متوسط & - , $9 \leqslant \mathrm{~V}$. & $r, 10$ & الشفافية & 1 & 1 \\
\hline متوسط & $1, \cdot \times 1$ & $r, .9$ & المشاركة & r & r \\
\hline متوسط & $1, .0 \varepsilon$ & $r, .9$ & الفعالية والكفاءة & $r$ & $r$ \\
\hline متوسط & $1, .94$ & $r, 91$ & التنافسية & $\varepsilon$ & $\varepsilon$ \\
\hline متوسط & . 917 & $r, .1$ & مبادئ الحوكمة & & \\
\hline
\end{tabular}

يبين الجدول (11) أن درجة تطبيق مبادئ الحوكمة في الجامعات الأردنية الحكومية جاءت بمستوى متوسط، وبمتوسط حسابي بلغ (م . ,r)، حيث

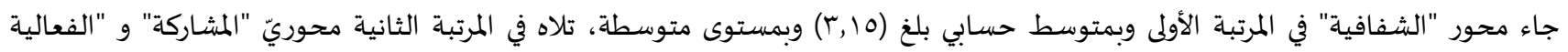

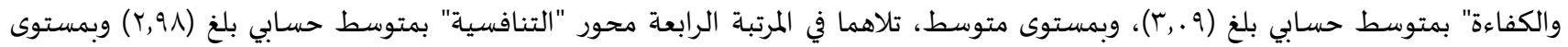

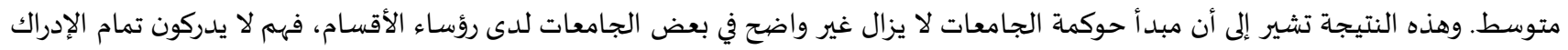

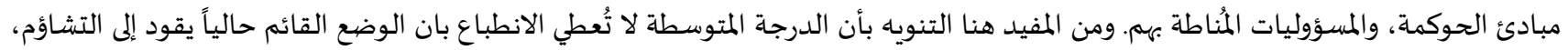

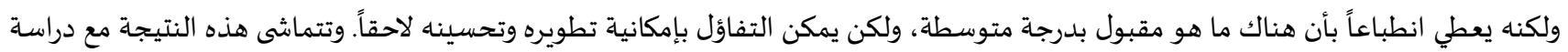

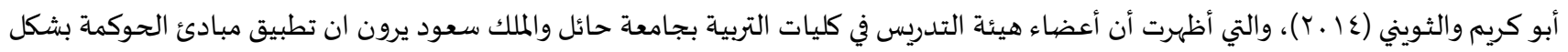

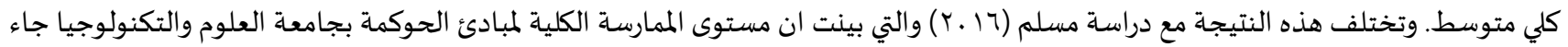

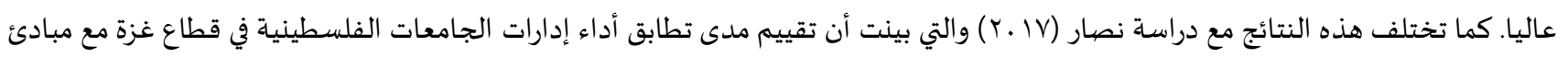

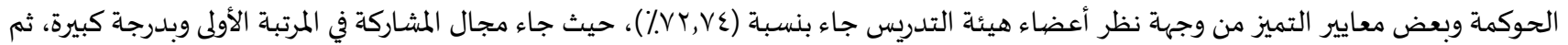

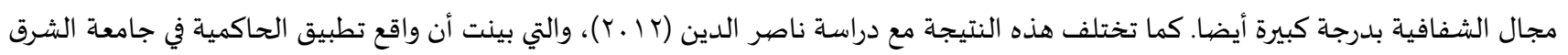
الأوسط، من وجهاة نظر أفراد عينة الدارسة ككل كان مرتفعا بشكل عام. وقد تم حساب المتوسطات الحسابية والانحرافات المعيارية لتقديرات أفراد عينة الدراسة على فقرات كرئهات كل محور على حدة، حيث كانت على على النحو 
جدول (r () ) المتوسطات الحسابية والانحر افات المعيارية المتعلقة بالشفافية مرتبة تنازلياً حسب المتوسطات الحسابية

\begin{tabular}{|c|c|c|c|c|c|}
\hline 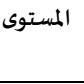 & المعياري & المستوسي & 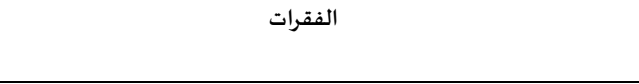 & 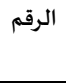 & الرتبة \\
\hline متوسط & $1, \cdot \pi$ & $r, r_{0}$ & يوفر رئيس القسم نظامأ للإعلام باللوائح والقوانين المنظمة للعمل في الجامعة. & 1 & 1 \\
\hline متوسط & $\cdot, 9 \wedge 1$ & $r, 19$ & يقدم رئيس القسم توصيفاً وظيفياً واضحاً لمهام كل وظيفة. & r & $r$ \\
\hline متوسط & $1, . \Sigma \varepsilon$ & $r, 11$ & يفصح رئيس القسم عن سياسة المكافآت. & $r$ & $r$ \\
\hline متوسط & $1,1.1$ & $r, i r$ & يقوم رئيس القسم بنشر الممزانية السنوية في موعدها. & 7 & $\varepsilon$ \\
\hline 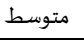 & $1, \cdot \wedge \varepsilon$ & $r, 1$. & يتيح رئيس القسم تبادل المعلومات على كافة المستويات الإدارية. & $\varepsilon$ & $\circ$ \\
\hline 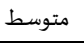 & $1, . r$. & $r, . v$ & يعمل رئيس القسم في الصفحة الإلكترونية و يتم تحديثها بشكل مستمر. & $\circ$ & 7 \\
\hline متوسط & $\cdot, 9 \leqslant \mathrm{~V}$ & $r, 10$ & الشفافية & & \\
\hline
\end{tabular}

يبين الجدول (I ) أن محور "الشفافية" جاء في المرتبة الأولى بمتوسط حسابي (r, 10) وبمستوى متوسط، فقد حصلت الفقرة رقم (1) على المرتبة

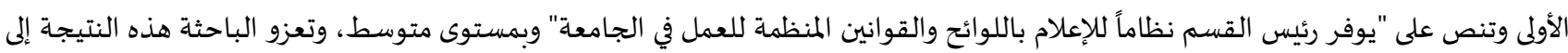

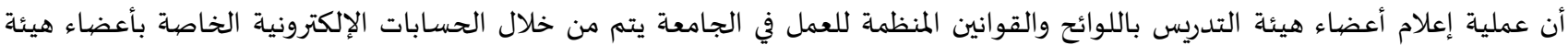

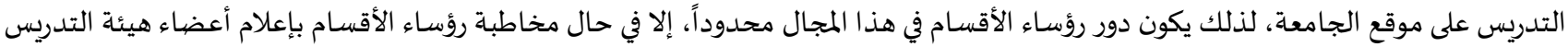

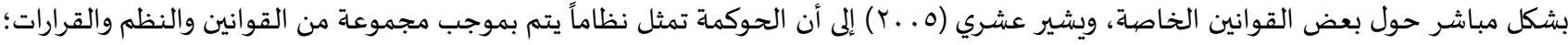

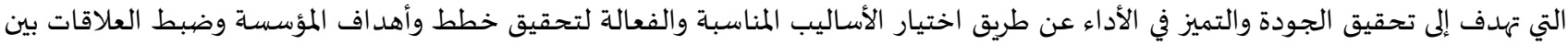

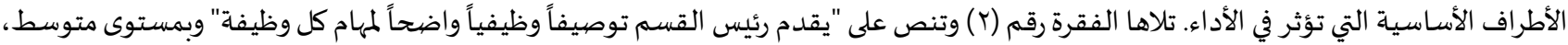

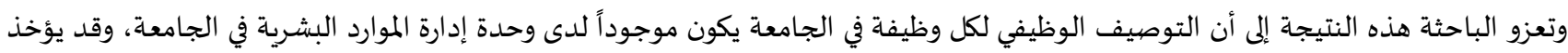

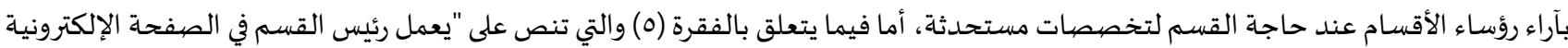

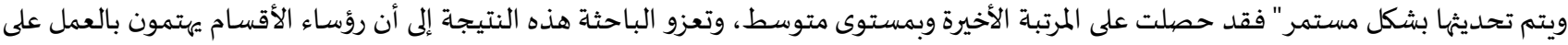

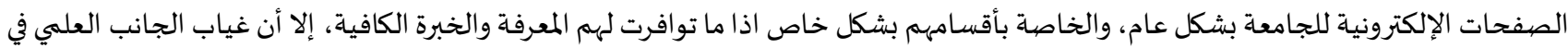

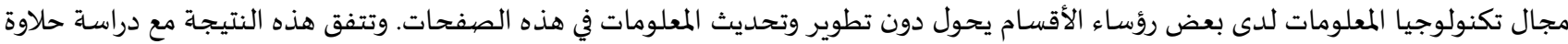

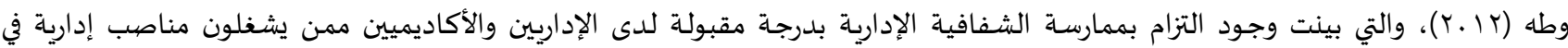
الجامعات الفلسطينية. المحور الثاني: المشاركة

جدول (rا ): المتوسطات الحسابية والانحر افات المعيارية المتعلقة بالمشاركة مرتبة تنازلياً حسب المتوسطات الحسابية

\begin{tabular}{|c|c|c|c|c|c|}
\hline 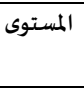 & المعياري & المستوسطي & 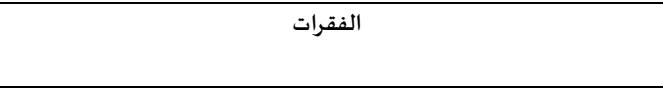 & 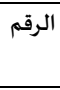 & 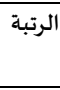 \\
\hline متوسط & $1,1 \leqslant \mathrm{~V}$ & $r, 10$ & يُسمحح لكافة أعضاء هيئة التدريس بمناقشة القرارات وتعديلها. & 1 & 1 \\
\hline متوسط & $1,1 \mathrm{VV}$ & $r, 1 \varepsilon$ & والأكاديمية. & $\varepsilon$ & $r$ \\
\hline متوسط & 1,171 & r,IT & يستخدم رئيس القسم أسلوب الحوار الديمقراطي عند كافة المعاملات. & r & $r$ \\
\hline متوسط & $1, r r \varepsilon$ & $r, \cdot 1$ & يشجع رئيس القسم جميع أعضاء هيئة التدريس على المشاركة البناءة والإيجابية. & 7 & $\varepsilon$ \\
\hline متوسط & $1,1 \mathrm{VA}$ & $r, \cdot v$ & يُسُمح لكافة أعضاء هيئة التدريس بالتعبير عن آرائهم. & $r$ & 0 \\
\hline متوسط & $1,1 \wedge \mathrm{V}$ & $r, . \varepsilon$ & يستعى رئيس القسم للإشراك الأطراف المعنية (العاملين - الطلبة- مؤسسات & $\circ$ & 7 \\
\hline متوسط & $1, r \cdot V$ & $r, \cdot r$ & تدعم رئاسة القسم إنجاز الأعمال بروح الفريق. & $\mathrm{r}$ & $\mathrm{v}$ \\
\hline متوسط & $1, . \times 1$ & $r, .9$ & المشاركة & & \\
\hline
\end{tabular}

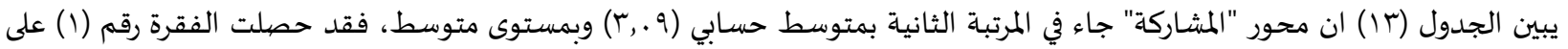

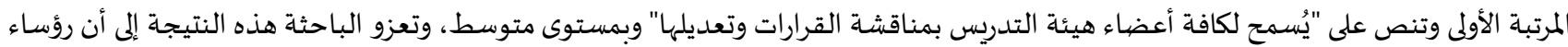

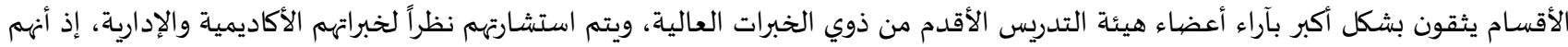

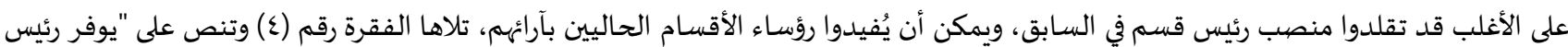

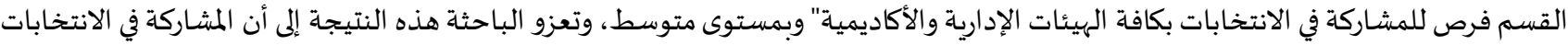

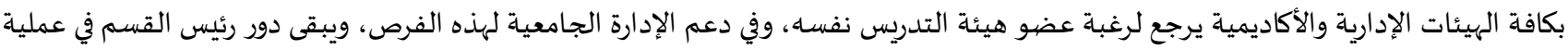
تسهيل وتيسير هذه العملية وتقديم الدعم لهم، أما فيما يتعلق بالفقرة (V) والتي تنص على "تدعم رئاسة القسم إنجاز الأعمال بروح الفريق" فقداند 
حصلت على المرتبة الأخيرة وبمستوى متوسط، وهذه النتيجة تشير إلى غياب عنصر العمل بروح الفريق في بعض الأقسام الأكاديمية، إذ يلجا أعضياء هيئة التدريس إلى العمل الفردي في إنجاز الأعمال نظراً لعدم توفر الظروف والإمكانات والوقت الكيه الكافي لإنجاز الأعمال بشكل جماعي.

المحور الثالث: الفعالية والكفاءة

جدول (ع ا): المتوسطات الحسابية والانحر افات المعيارية المتعلقة بالفعالية والكفاءة مرتبة تنازلياً حسب المتوسطات الحسابية

\begin{tabular}{|c|c|c|c|c|c|}
\hline 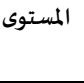 & المعياري & المسابي & 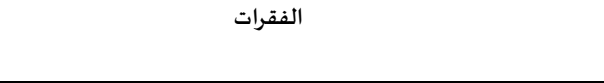 & 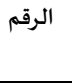 & الرتبة \\
\hline متوسط & $1,1 \ldots$ & $r, 17$ & يعمل رئيس القسم بوضيع الأهداف وفق الإمكانات المتاحة. & r & 1 \\
\hline متوسط & $1, Y \cdot 0$ & $r, 11$ & يسعى رئيس القسم لتحسبن التخطيط للموارد البشرية واستثمارها. & 7 & $r$ \\
\hline 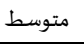 & $1,17 \varepsilon$ & $r, .9$ & يوفر رئيس القسم برامج تأهيلية وتدرببية لأعضاء هيئة التدريس. & $\circ$ & $r$ \\
\hline متوسط & $1,1 \leqslant \varepsilon$ & $r, .1$ & يوفر رئيس القسم خططاً بعيدة المدى لتطوير مستوى الأداء. & 1 & $\varepsilon$ \\
\hline متوسط & 1,101 & $r, \cdot v$ & يعمل رئيس القسم بتنظيم استخدام موارد الجامعة المالية المتاحة بعناية. & r & 0 \\
\hline متوسط & 1,110 & $r, \cdot v$ & يعمل رئيس القسم بوضع خطط لتطوير موارد الجامعة المالية. & $\varepsilon$ & $\circ$ \\
\hline متوسط & I,YTr & $r, .0$ & يوفر رئيس القسم نظاماً للتعرف على الاحتياجات لأعضاء هيئة التدريس. & v & v \\
\hline متوسط & $1, .0 \varepsilon$ & $r, .9$ & الفعالية والكفاءة الفاءة & & \\
\hline
\end{tabular}

يبين الجدول (عا) أن محور "الفعالية والكفاءة" جاء أيضاً في المرتبة الثانية بمتوسط حسابي (Y. . (r) وبمستوى متوسط، فقد حصلت الفقرة

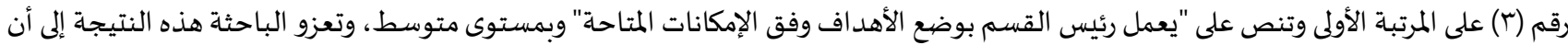

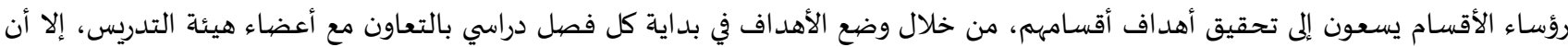
الدعم المادي والمخصصات التي تُحَدد لكل قسم تضع رؤساء الأقسام في دائرة محصورة لتحقيق أهداف محدددة ضمن الإمكانيات المتاحة، تلاها الفقرة رقم (7) وتنص على "يسعى رئيس القسم لتحسبن التخطيط للموارد البشرية واستثمارها" وبمستوى متوسط، وتعزو الباحثة هذه النتيجة إلى أن عملية تخطيط الموارد البشرية تتم من خلال أقسام الموارد البشرية في الجامعات، وهي المعنية بعمليات التخطيط، والاستقطاب، والتعيين، ويتم الأخذ بآراء

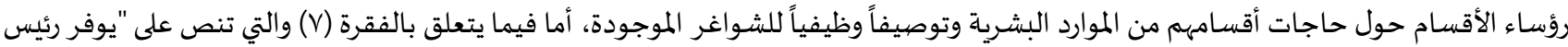

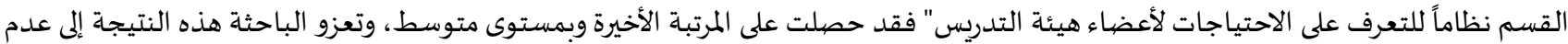
وجود آلية واضحة لرؤساء الأقسام للتعرف على احتياجات أعضاء هيئة التدريس، إلا في الاجتماعات الدورية التي يعقدها رؤساء الأقسام مع أعضاء هيئة التدريس، والتي من خلالها يتم التعرف على احتياجاتهم. المحور الر ابع: التنافسية

جدول (10): المتوسطات الحسابية والانحر افات المعيارية المتعلقة بالتنافسية مرتبة تنازلياً حسب المتوسطات الحسابية

\begin{tabular}{|c|c|c|c|c|c|}
\hline 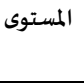 & 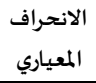 & المتوسط المسبي & 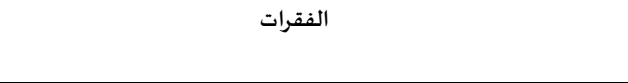 & 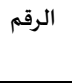 & 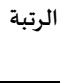 \\
\hline متوسط & 1,100 & $r, . \varepsilon$ & يدعم رئيس القسم استخدام المستحدثات التكنولوجيا الحديثة. & $r$ & 1 \\
\hline متوسط & $1,1 v \varepsilon$ & $r, \cdot r$ & يحرص رئيس القسم على استقطاب الكفاءات العلمية من ذوي التخصصات & $\varepsilon$ & $r$ \\
\hline متوسط & I,Y.r & r,qv & يشجع رئيس القسم الأبحاث الموجهة لخدمة المجتمع. & r & $r$ \\
\hline متوسط & 1,190 & r,qV & يتبنى رئيس القسم معايير الجودة في نظامها الاكاديمي. & $\circ$ & $r$ \\
\hline متوسط & 1,Yrr & $r, 97$ & يعقد رئيس القسم الاتفاقيات مع الجامعات الرائدة إقليمياً وعالمياً. & 1 & 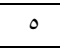 \\
\hline متوسط & 1, rov & r,A9 & يسعى رئيس القسم لتطبيق أنظمة الاعتماد العالمية. & 7 & 7 \\
\hline متوسط & $1, .9 r$ & $r, 91$ & التنافسية & & \\
\hline
\end{tabular}

يبين الجدول (10) أن محور "التنافسية" جاء في المرتبة الرابعة والأخيرة بمتوسط حسابي (Y,9ᄉ) وبمستوى متوسط، فقد حصلت الفقرة رقم (r) على المرتبة الأولى وتنص على "يدعم رئيس القسم استخدام المستحدثات التكنولوجيا الحديثة" وبمستوى متوسط، وتعزو الباحثة هذه النتيجة إلى أن

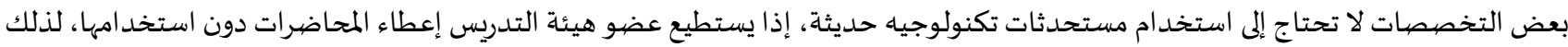
فقد حصلت هذه الفقرة على درجة تقدير متوسطة نظرا لعدم توفر المستحدثات التكنولوجية بشك كافي لجميع الأقسام. تلاها الفقرة رقم (ع) وتنص على "يحرص رئيس القسم على استقطاب الكفاءات العلمية من ذوي التخصصيات المختلفة" وبمستوى متوسط، وتعزو الباحثة هذه النتيجة المتوسطة إلى أن عملية الاستقطاب تتدخل فيها جهات متعددة غير رئيس القسم، إلا أن رؤساء الأقسام يسعون لأن يكون الكادر التدريسي مؤهلا وذي كفاءات

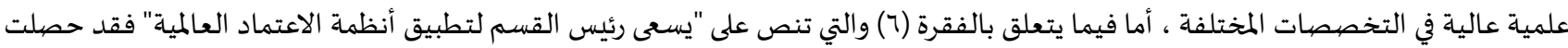
على المرتبة الأخيرة وبمستوى متوسط، وهذه النتيجة تشير إلى حاجة رؤساء الأقسام إلى الدعم المادي والعلمي في مجال تطبيق أنظمة الاعتماد العالمية، 
إذ يحتاج رؤساء الأقسام إلى التنور بمفاهيم الاعتماد العالمي وطرق تنفيذه، بالإضافة إلى توفير الدعم المالي للأقسام لتوفير كافة الاحتياجات لتحقيق مبدا الاعتماد والجودة. السؤال الر ابع: هل هناك فروق ذات دلالة إحصائية عند مستوى الدلالة (ه . . = م) بين متوسطات أفراد عينة الدراسـة في تحديد درجة تطبيق

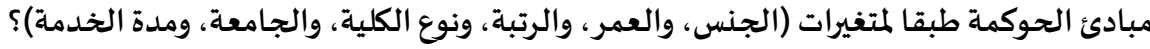

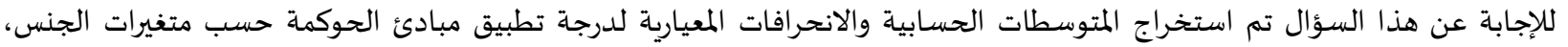
والعمر، والرتبة، ونوع الكلية، والجامعة، ومدة الخدمة، والجدول هدول أدناه يوضح ذلك الك.

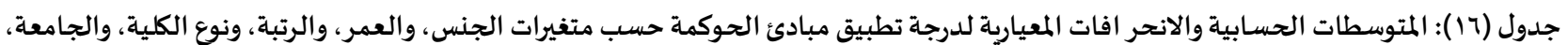
ومدة الخدمة

\begin{tabular}{|c|c|c|c|c|c|c|c|}
\hline مبادئ الحوكمة & التنافسية & الفعالية والكفاءة & المشـاركة & الشفافية & & & \\
\hline$r, 1 \Lambda$ & $r, \cdot V$ & $r, r$. & $r, r$. & $r, r r$ & س س & ذكر & الجنس \\
\hline., 900 & $1, .9 \mathrm{r}$ & 1,.r. & $1, .77$ &., $91 \mathrm{~V}$ & $\varepsilon$ & & \\
\hline$r, 10$ & $r, V 7$ & $r, \Lambda \varepsilon$ & $r, 10$ & $r, 97$ & س & \multirow{2}{*}{ أنثى } & \\
\hline., 991 & $1, .7 \varepsilon$ & $1, .91$ & $1, . \varepsilon \wedge$ & -,994 & $\varepsilon$ & & \\
\hline$r, 19$ & $r, i r$ & $r, 10$ & $r, r r$ & $r, r Y$ & س & \multirow[t]{2}{*}{ •r- اقل من . ع سنة } & العمر \\
\hline . 917 & $1, .87$ & $1, .70$ & $1, . V Y$ & -,9人र & $\varepsilon$ & & \\
\hline$r, . \varepsilon$ & $r, 9 T$ & $r, .7$ & $r, . \varepsilon$ & $r, 11$ & س & \multirow[t]{2}{*}{ ـع سنة فاكثر } & \\
\hline., $9 \times 1$ & $1, .9 \varepsilon$ & $1, .01$ & $1, .79$ & .,9rr & $\varepsilon$ & & \\
\hline$r, 1 \Lambda$ & r,IV & $r, 10$ & $r, 17$ & $r, r \varepsilon$ & س & \multirow[t]{2}{*}{ أستاذ مساعد } & \multirow[t]{3}{*}{ الرتبة الأكاديمية } \\
\hline $1, . r$. & 1,110 & $1,1 T V$ & $1, .9 \varepsilon$ & $1, .1 r$ & $\varepsilon$ & & \\
\hline$r, . r$ & $r, \wedge 9$ & $r, 99$ & $r, 1$. & $r, 11$ & س & \multirow[t]{2}{*}{ أستاذ مشـارك } & \\
\hline . ,9Vr & $1, . \varepsilon 9$ & $1, . \varepsilon \varepsilon$ & $1, . v V$ &., 970 & $\varepsilon$ & & \\
\hline$r, .7$ & $r, 9 \varepsilon$ & r,IT & $r, .0$ & $r, l \varepsilon$ & س س & \multirow[t]{2}{*}{ أستاذ } & \\
\hline .,90Y & 1,1.r & $1, \cdot T \varepsilon$ & $1, .71$ &., 9.0 & $\varepsilon$ & & \\
\hline$r, q$. & r,vq & $r, 91$ & $r, q$. & $r, 99$ & س س & حكومية & الجامعة \\
\hline - ,9人ץ & $1, .99$ & $1, . \varepsilon 0$ & $1, .10$ &., $9 \vee$. & $\varepsilon$ & & \\
\hline$r, 07$ & $r, \varepsilon V$ & $r, O V$ & $r, 7$. & $r, 09$ & س & \multirow[t]{2}{*}{ خاصة } & \\
\hline ., $\mathrm{VAl}$ & $\cdot, 9 \cdot 1$ & -,QYT & $\cdot, \wedge \varepsilon \varepsilon$ & $\cdot, \mathrm{VYT}$ & $\varepsilon$ & & \\
\hline$r, 90$ & $r, \wedge 9$ & $r, .$. & $r, 91$ & $r, 99$ & س & علمية & \multirow[t]{3}{*}{ نوع الكلية } \\
\hline $1, . r \Lambda$ & I,IVY & $1,|T|$ & $1, .19$ &., 91. & $\varepsilon$ & & \\
\hline$r, r \varepsilon$ & $r, 10$ & r, ro & $r, \leqslant 7$ & $r, \varepsilon V$ & س & \multirow[t]{2}{*}{ إنسانية } & \\
\hline ., $\mathrm{VYq}$ & $\cdot, \wedge \wedge 9$ & $\cdot, \wedge \wedge \varepsilon$ & .,9TV & . $\mathrm{\vee} \wedge 9$ & $\varepsilon$ & & \\
\hline$r, \cdot r$ & $r, 9 \varepsilon$ & $r, 99$ & $r, . \varepsilon$ & $r, 11$ & س & \multirow[t]{2}{*}{ اقل من ـ ا سنوات } & \multirow[t]{2}{*}{ مدة الخدمة } \\
\hline $1, .11$ & $1,1.1$ & $1, .9 \wedge 1$ & $1, .94$ & $1, \ldots r$ & $\varepsilon$ & & \\
\hline$r, 1 \varepsilon$ & $r, . r$ & $r, 1 \Lambda$ & $r, 1 \varepsilon$ & $r, r$. & س & \multirow[t]{2}{*}{ 10سنوات فاكثر } & \\
\hline •, १६। & $1, \cdot 10$ & $1, \ldots \varepsilon$ & $1, .0$. & 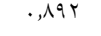 & $\varepsilon$ & & \\
\hline
\end{tabular}

يبين الجدول (7) تبايناً ظاهرياً في المتوسطات الحسابية والانحرافات المعيارية لدرجة تطبيق مبادئ الحوكمة بسبب اختلاف فئات متغيرات الجنس، والعمر ، والرتباة، ونوع الكلية، والجامعاة، ومدة الخدمة.

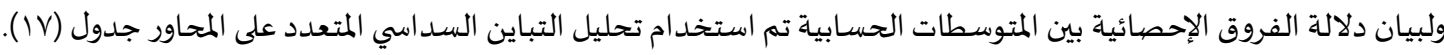

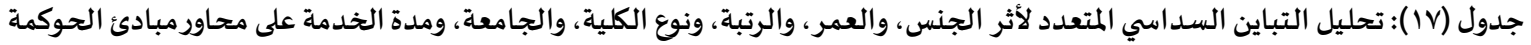

\begin{tabular}{|c|c|c|c|c|c|c|}
\hline الإحصائية الدلالة & قيمة ف & متوسط المربعات & الحربة & مجموع المربعات & المحاور & مصدر التباين \\
\hline., 790 & $1,1 \ldots$ & . AV & 1 & $\cdot, \lambda \vee \varepsilon$ & الشفافية & الجنس \\
\hline., 110 & 1,870 & $1, V V \varepsilon$ & 1 & $1, V V \varepsilon$ & المشاركة & هوتلنج=9 ., . \\
\hline., 114 & $r, 0 \leq 7$ & r,07. & 1 & r,07. & الفعالية والكفاءة & $.077=\tau$ \\
\hline ת & $r, r 90$ & $r, 090$ & 1 & $r, 090$ & التنافسية & \\
\hline
\end{tabular}




\begin{tabular}{|c|c|c|c|c|c|c|}
\hline., , OV & ,.,HT &.,.$r 7$ & 1 &.,.$Y 7$ & الشفافية & العمر \\
\hline., 940 & $\ldots, \ldots$ & $\ldots V$ & 1 & $\ldots, \ldots$ & المشاركة & هوتلنج= r . , . \\
\hline$\cdot, \vee .$. &., $1 \leqslant 9$ &., 10. & 1 &., 10 & الفعالية والكفاءة &., $90 .=\tau$ \\
\hline., 109 &., $.9 \varepsilon$ &., $1 . r$ & 1 &., $1 . r$ & التنافسية & \\
\hline . YrA & $1, \varepsilon \varepsilon Y$ & $1,1 \leqslant 7$ & r & $r, r q 1$ & الشفافية & الرتبة الأكاديمية \\
\hline . & $1, r \leq 7$ & 1, ror & $r$ & $r, V \cdot \varepsilon$ & المشاركة & ويلكس= =9VI, \\
\hline., 199 & $1, T \pi r$ & $1,7 \pi r$ & r & r,ז & الفعالية والكفاءة & .,$Y \Lambda \backslash=\tau$ \\
\hline.,.$\leqslant V$ & $r, .90$ & r, ros & $r$ & $7, Y \cdot 1$ & التنافسية & \\
\hline$\ldots$ & $10,0 \wedge \varepsilon$ & 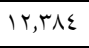 & 1 & 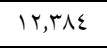 & الشفافية & الجامعة \\
\hline$\ldots$ & $10, v \cdot 9$ & $10, V \wedge \varepsilon$ & 1 & $10, V \wedge \varepsilon$ & المشاركة & هوتلنج=|7 > ,. \\
\hline.,$\ldots$ & $\mid 9, \leq 01$ & $19,00 \mathrm{r}$ & 1 & $19,00 Y$ & الفعالية والكفاءة & $\ldots, \ldots l=\tau$ \\
\hline 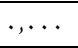 & 17,171 & $|V, O Y|$ & 1 & $|V, 0 Y|$ & التنافسية & \\
\hline.,$\ldots$ & $1 r, 77 \Lambda$ & $1 ., 171$ & 1 & $1 ., \lambda 71$ & الشفافية & نوع الكلية \\
\hline.,$\ldots$ & IT,O.Y & IT,OTY & 1 & Ir,OTr & المشاركة & هوتلنج= 9 . , . \\
\hline . & $1, \varepsilon r q$ & $1, \varepsilon \leqslant V$ & 1 & $1, \varepsilon \leqslant V$ & الفعالية والكفاءة & $\cdot, \cdots=\tau$ \\
\hline .,$Y \leqslant 7$ & 1,ro. & $1, \varepsilon 7 \pi$ & 1 & $1, \varepsilon 7 \pi$ & التنافسية & \\
\hline., 111 & r,07. & $r, \cdot r \varepsilon$ & 1 & $r, . r \varepsilon$ & الشفافية & مدة الخدمة \\
\hline.,.$r \varepsilon$ & $\varepsilon, 010$ & $\varepsilon, 0$, & 1 & $\varepsilon, 0$, & المشاركة & هوتلنج=|7 | ., \\
\hline , . . vo & $r, 191$ & $r, r \mid \varepsilon$ & 1 & $r, T \backslash \varepsilon$ & الفعالية والكفاءة & .,YAY $=\tau$ \\
\hline \multirow[t]{9}{*}{., .0} & $r, \wedge \wedge \varepsilon$ & $\varepsilon, Y . q$ & 1 & $\varepsilon, Y . q$ & التنافسية & \\
\hline & &., 190 & rrq & $r 71, \varepsilon \leqslant 7$ & الشفافية & الخطأ \\
\hline & & $1, \ldots 0$ & rrq & Tr.,OTV & المشاركة & \\
\hline & & $1, \ldots 0$ & rrq & $r r ., V .$. & الفعالية والكفاءة & \\
\hline & & $1, . \wedge \varepsilon$ & rrq & ro7,0 $0 \leqslant 9$ & التنافسية & \\
\hline & & & Tוז & $r \cdot 1,7 . r$ & الشفافية & الكلي \\
\hline & & & Trר & 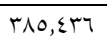 & المشاركة & \\
\hline & & & Trו & $r V r, .7 T$ & الفعالية والكفاءة & \\
\hline & & & רוד & $\varepsilon \ldots, \varepsilon r V$ & التنافسية & \\
\hline
\end{tabular}

يتبين من الجدول (IV) الآتي:

عدم وجود فروق ذات دلالة إحصائية (ه . . = م) تعزى لأثر الجنس في جميع المحاور. وهذه النتيجة تعني أن افراد عينة الدراسة من أعضاء هيئة العادية

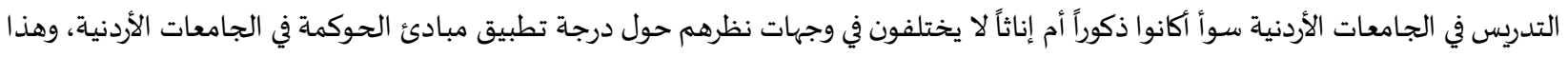

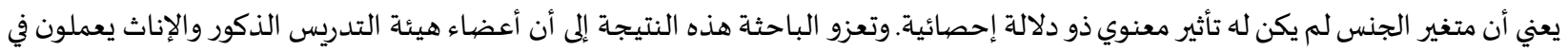

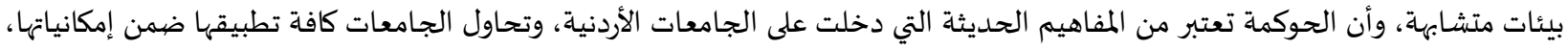

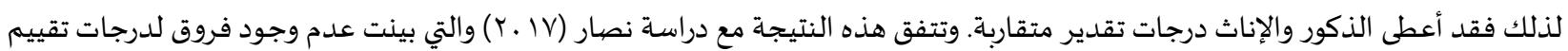

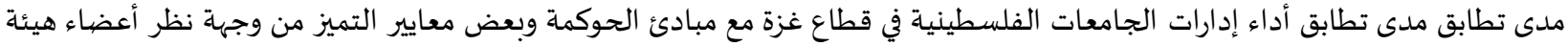

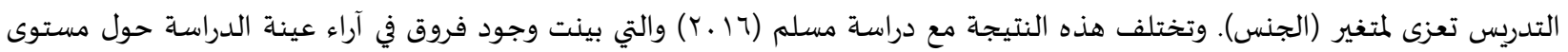
ممارسة الحوكمة وفقا لمتغيرات الجنس.

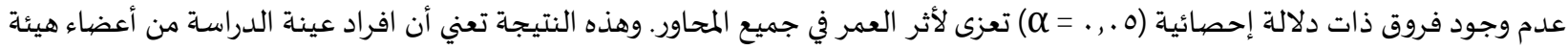

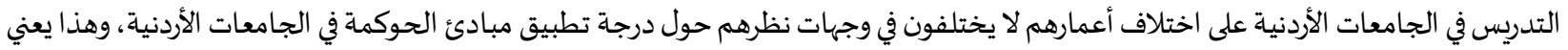

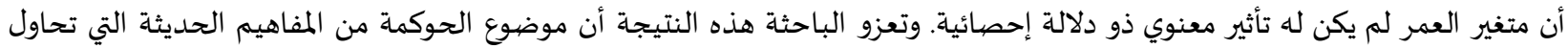

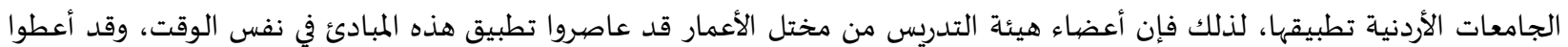
درجات تقدير متشابهة. عدم وجود فروق ذات دلالة إحصائية (0 . . = م) تعزى لأثر الرتبة الأكاديمية في جميع المحاور باستثناء التنافسية، وتعزو الباحثة هذه النتيجة

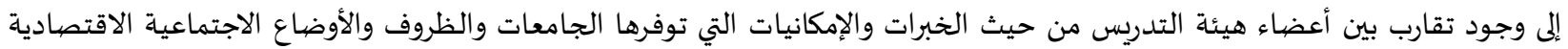
والسياسية، ونفس البيئة الثقافية، والارتباط بنفس السياسات والفلسفات والإجراءات، لذلك نجد أن إجاباتهم متقاربة حول درجة تطبيق

r. 
مبادئ الحوكمة في الجامعات الأردنية. ولبيان الفروق الزوجية الدالة إحصائيا بين المتوسطات الحسابية تم استخدام المقارنات البعدية بطريقة

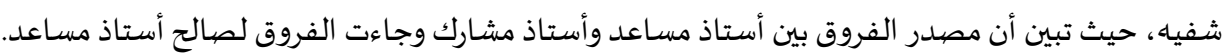
وجود فروق ذات دلالة إحصائية (0., . = م) تعزى لأثر الجامعة في جميع المحاور وجاءت الفروق لصالح الجامعات الخاصة. وتعزو الباحثة هذه

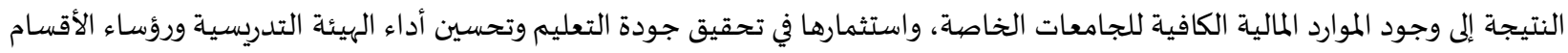

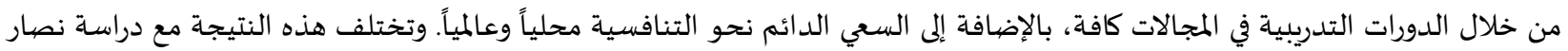

(Y ا I التي بينت عدم وجود فروق لدرجات تقييم مدى تطابق مدى تطابق أداء إدارات الجامعات مع مبادئ الحوكمة تعزى لمتغير (الجامعة). وجود فروق ذات دلالة إحصائية (ه., . = $\alpha)$ تعزى لأثر نوع الكلية في جميع المحاور باستثناء الفعالية والكفاءة، والتنافسية وجاءت الفروق

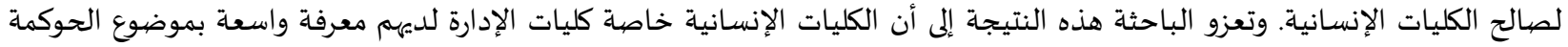

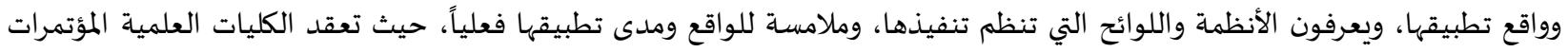
والندوات وورش العمل حول الحوكمة والجودة الشاملة والاعتماد الجامعي، مما يؤثر على تقييمهم لدرجة تطبيق مبادئ الحوكمة في الجامعات

عدم وجود فروق ذات دلالة إحصائية (ه . . . = م) تعزى لأثر مدة الخدمة في جميع المحاور باستثناء المشاركة، والتنافسية وجاءت الفروق لصالح

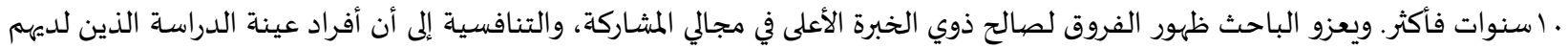

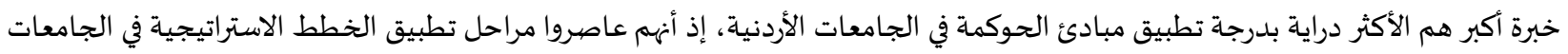

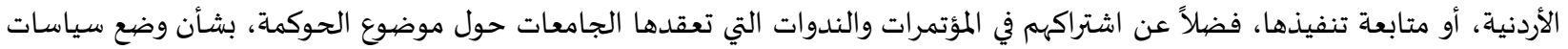

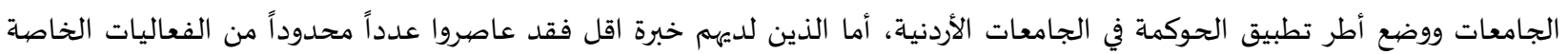

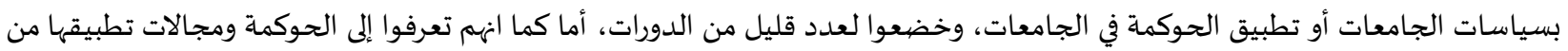

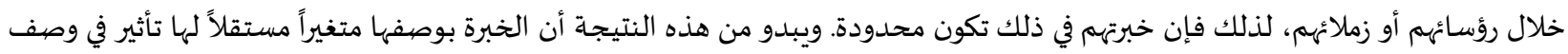

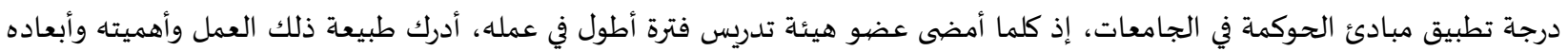

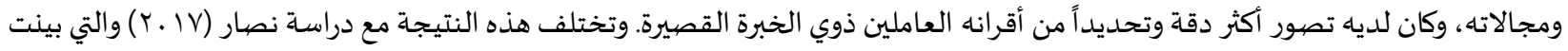

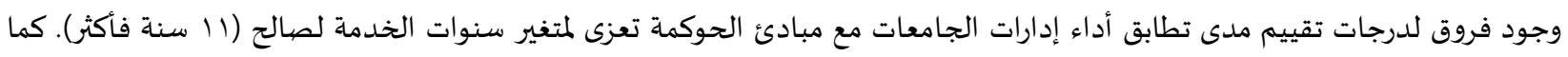

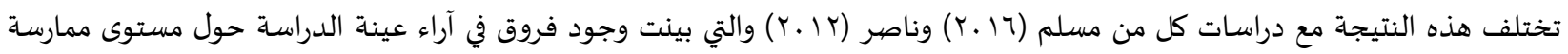
الحوكمة وفقا لمتغير سنوات الخدمة.

وبناءاً على ما توصلت إليه الدراسة من النتائج المذكورة تقدم الباحثة التوصيات التالية: ضرورة إعداد وتنفيذ برامج تدريبية لرؤساء الأقسام التربوية في المهارات المتعلقة بمجالات الدراسة التي حصلت على درجة تقدير متوسطة لرفع كفاءتهم وحصولههم وامتلاكهم لهذه المهارات

اعتماد الخبرة والمعرفة - بصفتها مؤشراً المواقع الإدارية القيادية في المؤسسات الجامعية. أن يقوم رؤساء الأقسام باستخدام صلاحياتهم في تعزيز الأداء الإيجابي لأعضاء هيئة التدريس ومحاسبة الأداء السلبي لما لذلك من دور تحفيزي فاعل. إيجاد وصف وظيفي واضح لطبيعة عمل رؤساء الأقسام الأكاديمية يفسر المهمات والاختصاصات الملقاة على عاتقهم. تعزيز واقع الأداء الإداري لرؤساء الأقسام في الجامعات الأردنية من خلال أساليب ووسائل قادرة على تعزيز هذه الواقع (ورشات عمل بين رؤساء الأقسام السابقين والجدد، نشرات ودراسات علمية حول دور رئيس القسيم). توفر دائرة خاصة لمتابعة تطبيق مبادئ الحوكمة بطريقة مباشرة ومقارنها بأداء رؤساء الأقسام وأعضاء هيئة التدريس. إجراء دراسات لاستقصاء الآثار السلبية الناتجـة عن عدم تطبيق الحوكمة في الجامعات. 


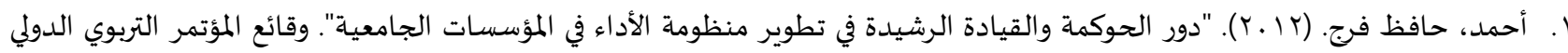

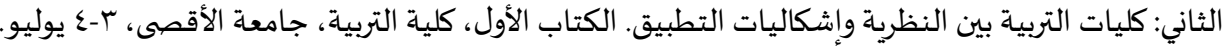

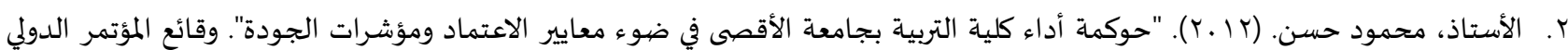

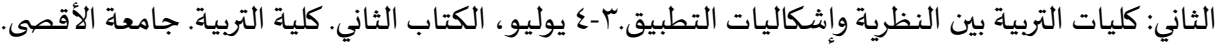

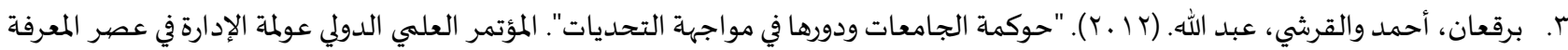

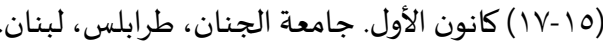

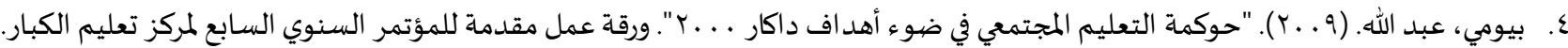

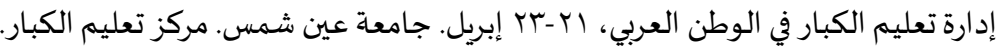

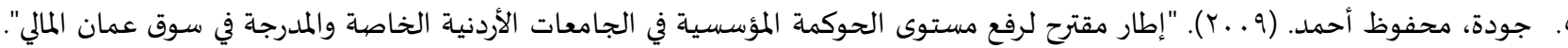
عمان، الأردن. T. حرب، نعيمة. (11. (r). "واقع الشفافية الإدارية ومتطلبات تطبيقها في الجامعات الفلسطينية بقطاع غزة"، رسالة ماجستير غير منشورة،

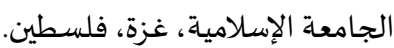

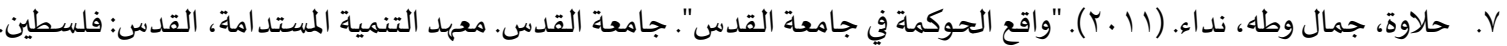

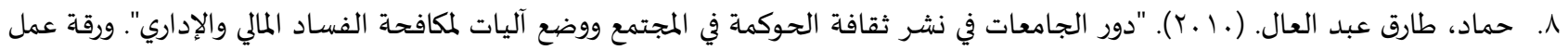

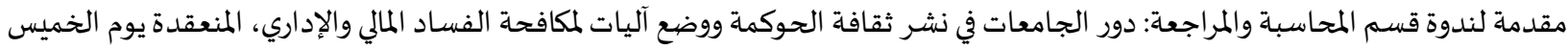

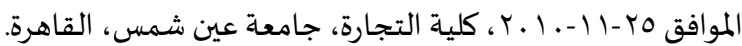

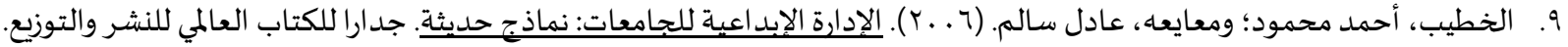

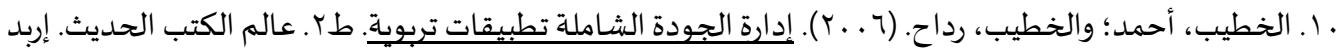

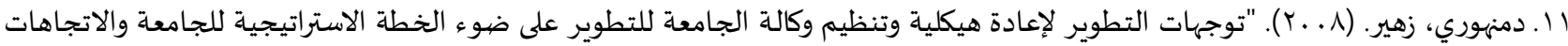

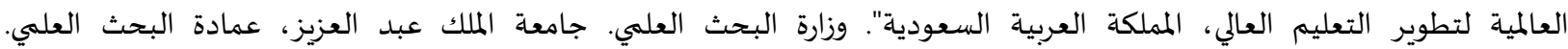
.www.kau.edu.sa/dsr

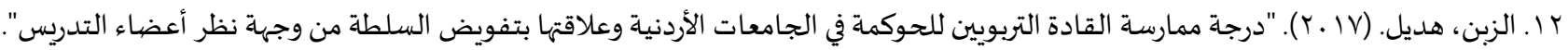
رسالة ماجستير غير منشورة. جامعة الشرق الأوسط. عمان: الأردن. rا. شرف، هناء. (10 (Y). "واقع تطبيق نظم الحوكمة ومعوقات ذلك في الجامعات الفلسطينية من وجهة نظر عمداء الكليات ورؤساء الأقسام في

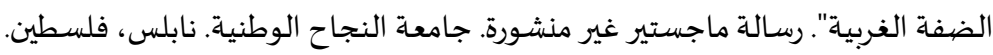
ع ا. صالح، محمد. (.1.ب). "مدى تطبيق مبدأ الإفصاح والشفافية من مبادئ حوكمة الشركات في شركة بئر المدور المساهمة المحدودة". رسالة

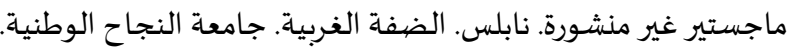

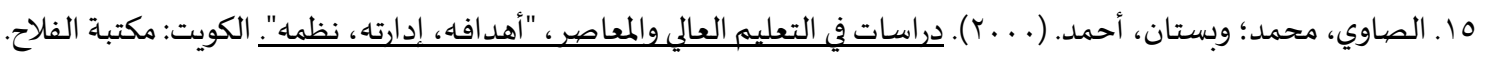
17 ا صلاحات، رافع يوسف. (r ا ـr). "واقع بيئة النزاهة والشفافية والمساءلة في الجامعات السعودية (الجامعات العامة والحكومية)". إشراف عزمي

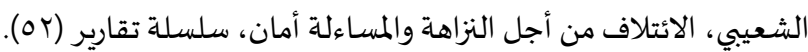

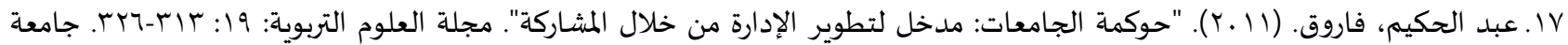
القاهرة

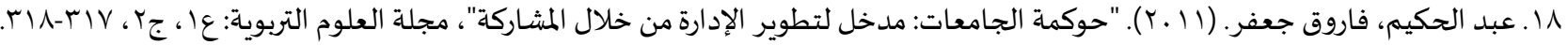

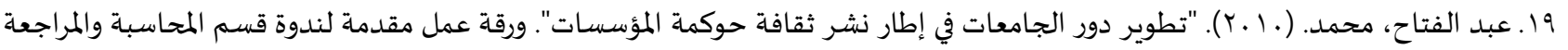

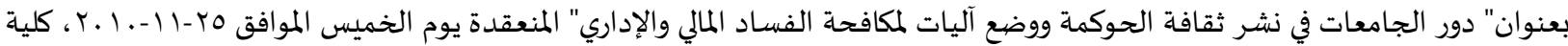

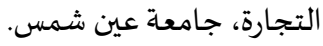

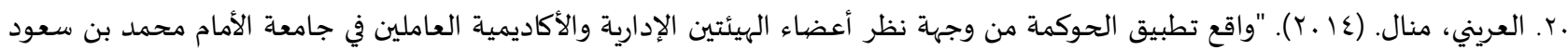

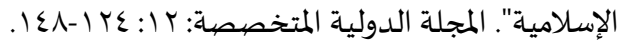


ا . عشري، مهران. (ه. . ب). "الحوكمة الجيدة وعلاقتها بتدعيم الجوانب الأخلاقية، المؤتمر الخامس لحوكمة الشركات المحاسبية وأبعادها

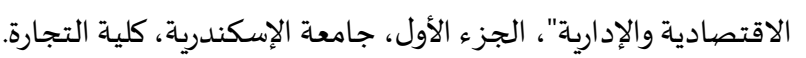

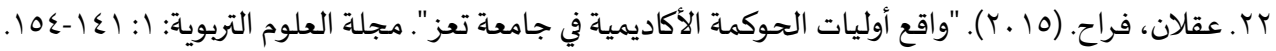

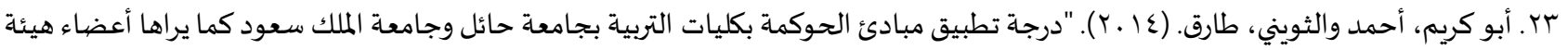

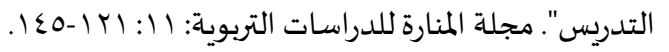

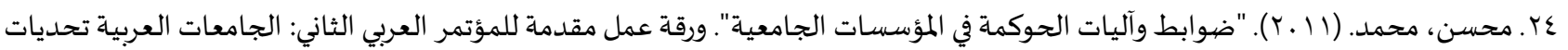

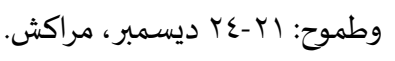

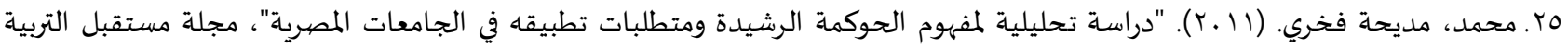

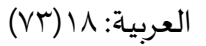

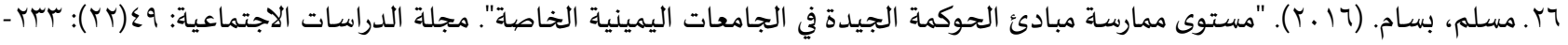
. TAY

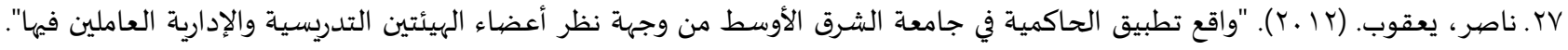
جامعة الشرق الأوسط، عمان، الأردن.

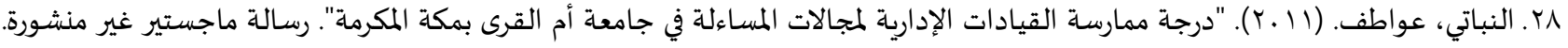

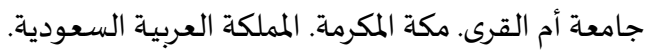

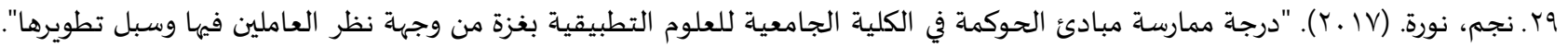
رسالة ماجستير غير منشورة. الجامعة الإسلامية. غزة، فلسطين.

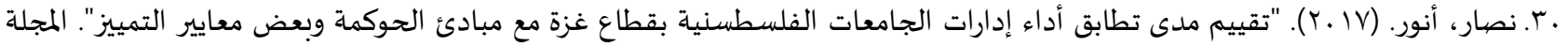

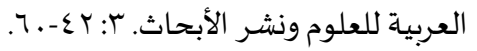
آ. يوسف، محمد حسن. (V . . . ). "محددات الحوكمة ومعاييرها مع إشارة خاصة لنمط تطبيقها في مصر ". بنك الاستثمار الدولي.

ثانياً: المراجع الأجنبية:

[1] Charbel. K \& Eliem. V. (2009)، "Surdents' Perception of théier Rôle In Université Gouvernance (Case of Libano)" ، Faculté of Management and Commercial Sciences، Université Saint Esprit de Kasli.

[2] Kevry. H، (2009) "The Good Governance Agenda of International Development Institutions”، Virginia، Old Dominion University، P.H.D dissertation.

[3] Middleton، C. R. (2010). “The Virtues of Student and Faculty Trustees”. Trusteeship، 18(4)، 24-27.

[4] Naga. V.R. (2006). "Pawan Yallaprgada and Sarada Vitukuru Departmaent of IT. Asurag Engineering College. Andhra Pradesh", Higher Education. 523-555.

[5] Nehme A، \& Charbel، S. (2009). "The Modern Gouvernance in Lebanese Universities “، Faculté of Management and Commercial Sciences، Université Saint Esprit de Kasli.

[6] Peter، M. (2000) “The Changing Roles Stakeholders in Dutch University Governance”، European Journal of Education، 35(4) :449-464, https://doi.org/10.1111/1467-3435.00039

[7] Shakeela، S. (2012). "Theoretical Arguments on Shared Université Gouvernance : An Observation of Université Gouvernance in Public Université in pakistan“ ، $2^{\text {nd }}$ International Conference on Hnumanities، Geography and Economic (ICHG2012) Singapore April 28-29. 


$$
\text { المجلة الدولية للدراسات التربوية والنفسية }
$$

International Journal of Educational \& Psychological Studies (EPS)

Journal Homepage: https://www.refaad.com/views/EPSR/Home.aspx

www.refaad.com

ISSN: 2520-4149 (Online) 2520-4130 (Print)

\title{
Administrative performance of the heads of the academic department chairs at Jordanian universities and its relationship with implementing principles of governance
}

\author{
Basheerah Hasan Okleh Megdadi \\ Ph.D. Student, Educational Administration, Faculty of Administration and Fundamentals of Education, \\ Yarmouk University, Jordan \\ basheerahmiqdadi@yahoo.com
}

Adnan Badri Alibrahim

Professor of Educational Administration, Faculty of Administration and Fundamentals of Education, Department of Educational Administration, Yarmouk University, Jordan

Received Date : $31 / 12 / 2019$

Accepted Date : 4/2/2020

DOI : https://doi.org/DOI:10.31559/EPS2020.8.1.1

\begin{abstract}
:
This study aimed to identify the administrative performance of the heads of academic departments in Jordanian universities and its relationship to the application of governance. The study used the descriptive approach، and a questionnaire of (61) items was applied to the sample of the study، that consists of (337) faculty members، who were selected randomly from Jordanian universities (Yarmouk، Science and Technology، Al-Bayt، Irbid National، Jidara). The results revealed that the level of administrative performance among the heads of academic departments in the Jordanian public universities was medium، and the results revealed that there are statistically significant differences on the administrative performance in the Jordanian universities due to (gender، and university type) While there were no statistically significant differences due to (age، academic rank، college type). The results showed that the degree of application of governance in the Jordanian universities was medium. the results revealed that there are statistically significant differences on the degree of application of governance due to (university، college type، years of service), while there were no significant differences attributed to (gender، age, and academic rank). The study recommended the necessity of preparing and implementing training programs for the heads of educational departments in skills related to the fields of study that have obtained an average degree of appreciation to raise their efficiency and their access and possession of these skills. Adopting experience and knowledge- as an indication of leadership positions in university institutions. And that department heads use their powers to enhance the positive performance of faculty members and account for negative performance because of this active catalytic role.
\end{abstract}

Keywords: Administrative Performance; Governance; Heads of Academic Departments; Jordanian Universities.

\section{References:}

[1] 'bd Alhkym, Farwq. (2011). "Hwkmh Aljam'at: Mdkhl Lttwyr Aledarh Mn Khlal Almsharkh". Mjlt Al'lwm Altrbwyh: 19: 313-326. Jam't Alqahrh

[2] 'bd Alhkym, Farwq J'fr. (2011). "Hwkmt Aljam'at: Mdkhl Lttwyr Aledarh Mn Khlal Almsharkh", Mjlt Al'lwm Altrbwyh: '1, $\mathrm{J} 2,317-318$.

[3] 'bd Alftah, Mhmd. (2010). "Ttwyr Dwr Aljam'at Fy Etar Nshr Thqafh Hwkmh Alm'ssat". Wrqt 'ml Mqdmh Lndwh Qsm Almhasbh Walmraj'h B'nwan" Dwr Aljam'at Fy Nshr Thqafh Alhwkmh Wwd' Alyat Lmkafhh Alfsad Almaly Waledary" Almn'qdh Ywm Alkhmys Almwafq 25-11-2010, Klyh Altjarh, Jam't 'yn Shms. 
[4] Al'ryny, Mnal. (2014). "Waq' Ttbyq Alhwkmh Mn Wjhh Nzr A'da' Alhy'tyn Aledaryh Walakadymyh Al'amlyn Fy Jam't Alamam Mhmd Bn S'ewd Aleslamyh". Almjlh Aldwlyh Almtkhssh: 12: 124-148.

[5] 'shry, Mhran. (2005). "Alhwkmh Aljydh W'laqtha Btd'ym Aljwanb Alakhlaqyh, Alm'tmr Alkhams Lhwkmh Alshrkat Almhasbyh Wab'adha Alaqtsadyh Waledaryh", Aljz' Alawl, Jam't Aleskndryh, Klyt Altjarh.

[6] 'qlan, Frah. (2015). "Waq' Awlyat Alhwkmh Alakadymyh Fy Jam't T'z". Mjlt Al'lwm Altrbwyh: 1: 141-154.

[7] Alastad, Mhmwd Hsn. (2012). "Hwkmt Ada' Klyt Altrbyh Bjam't Alaqsa Fy Dw' M'ayyr Ala'tmad Wm'shrat Aljwdh". Wqa" Alm'tmr Aldwly Althany: Klyat Altrbyh Byn Alnzryh Weshkalyat Alttbyq.3-4 Ywlyw, Alktab Althany. Klyt Altrbyh. Jam't Alaqsa.

[8] Ahmd, Hafz Frj. (2012). "Dwr Alhwkmh Walqyadh Alrshydh Fy Ttwyr Mnzwmh Alada' Fy Alm'ssat Aljam'yh". Wqa" Alm'tmr Altrbwy Aldwly Althany: Klyat Altrbyh Byn Alnzryh Weshkalyat Alttbyq. Alktab Alawl, Klyt Altrbyh, Jam't Alaqsa, 3-4 Ywlyw.

[9] Brq'an, Ahmd Walqrshy, 'bd Allh. (2012). "Hwkmt Aljam'at Wdwrha Fy Mwajht Althdyat". Alm'tmr Al'lmy Aldwly 'wlmh Aledarh Fy 'sr Alm'rfh (15-17) Kanwn Alawl. Jam't Aljnan, Trabls, Lbnan.

[10] Bywmy, 'bd Allh. (2009). "Hwkmt Alt'lym Almjtm'y Fy Dw' Ahdaf Dakar 2000". Wrqt 'ml Mqdmh Llm'tmr Alsnwy Alsab' Lmrkz T'lym Alkbar. Edart T'lym Alkbar Fy Alwtn Al'rby, 21-23 Ebryl. Jam't 'yn Shms. Mrkz T'lym Alkbar.

[11] Charbel. K \& Eliem. V. (2009), "Surdents' Perception of théier Rôle In Université Gouvernance (Case of Libano)" ، Faculté of Management and Commercial Sciences، Université Saint Esprit de Kasli.

[12] Dmnhwry, Zhyr. (2008). "Twjhat Alttwyr Le'adh Hyklyh Wtnzym Wkalh Aljam'h Llttwyr 'la Dw' Alkhth Alastratyjyh Lljam'h Walatjahat Al'almyh Lttwyr Alt'lym Al'aly, Almmlkh Al'rbyh Als'wdyh". Wzart Albhth Al'lmy. Jam't Almlk 'bd Al'zyz, 'madh Albhth Al'lmy. www.kau.edu.sa/dsr.

[13] Hlawh, Jmal Wth, Nda'. (2011). "Waq' Alhwkmh Fy Jam'eh Alqds". Jam't Alqds. M'hd Altnmyh Almstdamh, Alqds: Flstyn.

[14] Hmad, Tarq 'bd Al'al. (2010). "Dwr Aljam'at Fy Nshr Thqafh Alhwkmh Fy Almjtm' Wwd' Alyat Lmkafhh Alfsad Almaly Waledary". Wrqt 'ml Mqdmh Lndwh Qsm Almhasbh Walmraj'h: Dwr Aljam'at Fy Nshr Thqafh Alhwkmh Wwd' Alyat Lmkafhh Alfsad Almaly Waledary, Almn'qdh Ywm Alkhmys Almwafq 25-11-2010, Klyt Altjarh, Jam't 'yn Shms, Alqahrh.

[15] Hrb, N'ymh. (2011). "Waq' Alshfafyh Aledaryh Wmttlbat Ttbyqha Fy Aljam'eat Alflstynyh Bqta' Ghzh", Rsalt Majstyr Ghyr Mnshwrh, Aljam'eh Aleslamyh, Ghzh, Flstyn.

[16] Jwdh, Mhfwz Ahmd. (2009). "Etar Mqtrh Lrf' Mstwa Alhwkmh Alm'ssyh Fy Aljam'at Alardnyh Alkhash Walmdrjh Fy Swq 'man Almaly". 'man, Alardn.

[17] Kevry. H، (2009) “The Good Governance Agenda of International Development Institutions”، Virginia، Old Dominion University، P.H.D dissertation.

[18] Alkhtyb, Ahmd Mhmwd: Wm'ay'h, 'adl Salm. (2006). Aledarh Alebda'yh Lljam'at: Nmadj Hdythh. Jdara Llktab Al'almy Llnshr Waltwzy'.

[19] Alkhtyb, Ahmd: Walkhtyb, Rdah. (2006). Edart Aljwdh Alshamlh Ttbyqat Trbwyh. T2. 'alm Alktb Alhdyth. Erbd

[20] Abw Krym, Ahmd Walthwyny, Tarq. (2014). "Drjt Ttbyq Mbad' Alhwkmh Bklyat Altrbyh Bjam't Ha'l Wjam't Almlk S'wd Kma Yraha A'da' Hy'h Altdrys". Mjlt Almnarh Lldrasat Altrbwyh: 11: 121-145.

[21] Mhmd, Mdyhh Fkhry. (2011). "Drash Thlylyh Lmfhwm Alhwkmh Alrshydh Wmttlbat Ttbyqh Fy Aljam'at Almsryh", Mjlt Mstqbl Altrbyh Al'rbyh: 18(73)

[22] Mhsn, Mhmd. (2011). "Dwabt Walyat Alhwkmh Fy Alm'ssat Aljam'yh". Wrqt 'ml Mqdmh Llm'tmr Al'rby Althany: Aljam'at Al'erbyh Thdyat Wtmwh: 21-24 Dysmbr, Mraksh.

[23] Middleton، C. R. (2010). “The Virtues of Student and Faculty Trustees”. Trusteeship، 18(4)، 24-27.

[24] Mslm, Bsam. (2016). "Mstwa Mmarsh Mbad' Alhwkmh Aljydh Fy Aljam'at Alymynyh Alkhash". Mjlt Aldrasat Alajtma'yh: 49(22): 233-282.

[25] Naga. V.R. (2006). "Pawan Yallaprgada and Sarada Vitukuru Departmaent of IT. Asurag Engineering College. Andhra Pradesh", Higher Education. 523-555.

[26] Nasr, Y'qwb. (2012). "Waq' Ttbyq Alhakmyh Fy Jam't Alshrq Alawst Mn Wjht Nzr A'da' Alhy'tyn Altdrysyh Waledaryh Al'amlyn Fyha". Jam't Alshrq Alawst, 'man, Alardn.

[27] Alnbaty, 'watf. (2011). "Drjt Mmarsh Alqyadat Aledaryh Lmjalat Almsa'lh Fy Jam't Am Alqra Bmkh Almkrmh". Rsalt Majstyr Ghyr Mnshwrh. Jam't Am Alqra. Mkh Almkrmh. Almmlkh Al'rbyh Als'wdyh. 
[28] Nehme A. \& Charbel، S. (2009). “The Modern Gouvernance in Lebanese Universities “، Faculté of Management and Commercial Sciences، Université Saint Esprit de Kasli.

[29] Njm, Nwrh. (2017). "Drjt Mmarsh Mbad' Alhwkmh Fy Alklyh Aljam'yh Ll'lwm Alttbyqyh Bghzh Mn Wjht Nzr Al'amlyn Fyha Wsbl Ttwyrha". Rsalt Majstyr Ghyr Mnshwrh. Aljam'h Aleslamyh. Ghzh, Flstyn.

[30] Nsar, Anwr. (2017). "Tqyym Mda Ttabq Ada' Edarat Aljam'at Alflstsnyh Bqta' Ghzh M' Mbad' Alhwkmh Wb'd M'ayyr Altmyyz". Almjlh Al'rbyh Ll'lwm Wnshr Alabhath. 3: 42-60.

[31] Peter، M. (2000) “The Changing Roles Stakeholders in Dutch University Governance”. European Journal of Education. 35(4) :449-464, https://doi.org/10.1111/1467-3435.00039

[32] Salh, Mhmd. (2010). "Mda Ttbyq Mbda Alefsah Walshfafyh Mn Mbad' Hwkmh Alshrkat Fy Shrkh B'r Almdwr Almsahmh Almhdwdh". Rsalt Majstyr Ghyr Mnshwrh. Nabls. Aldfh Alghrbyh. Jam't Alnjah Alwtnyh.

[33] Alsawy, Mhmd؛ Wbstan, Ahmd. (2000). Drasat Fy Alt'lym Al'aly Walm'asr, "Ahdafh, Edarth, Nzmh". Alkwyt: Mktbt Alflah.

[34] Shakeela، S. (2012). "Theoretical Arguments on Shared Université Gouvernance : An Observation of Université Gouvernance in Public Université in pakistan“ ، $2^{\text {nd }}$ International Conference on Hnumanities، Geography and Economic (ICHG2012) Singapore April 28-29.

[35] Shrf, Hna'. (2015). "Waq' Ttbyq Nzm Alhwkmh Wm'wqat Dlk Fy Aljam'at Alflstynyh Mn Wjht Nzr 'mda' Alklyat Wr'sa' Alaqsam Fy Aldfh Alghrbyh". Rsalt Majstyr Ghyr Mnshwrh. Jam't Alnjah Alwtnyh. Nabls, Flstyn.

[36] Slahat, Raf'e Ywsf. (2012). "Waq' By'h Alnzahh Walshfafyh Walmsa'lh Fy Aljam'at Als'wdyh (Aljam'at Al'amh Walhkwmyh)". Eshraf 'zmy Alsh'yby, Ala'tlaf Mn Ajl Alnzahh Walmsa'lh Aman, Slslh Tqaryr (52).

[37] Ywsf, Mhmd Hsn. (2007). "Mhddat Alhwkmh Wm'ayyrha M' Esharh Khash Lnmt Ttbyqha Fy Msr". Bnk Alastthmar Aldwly.

[38] Alzbn, Hdyl. (2017). "Drjt Mmarsh Alqadh Altrbwyyn Llhwkmh Fy Aljam'at Alardnyh W'laqtha Btfwyd Alslth Mn Wjht Nzr A'da' Altdrys". Rsalt Majstyr Ghyr Mnshwrh. Jam't Alshrq Alawst. 'man: Alardn. 